

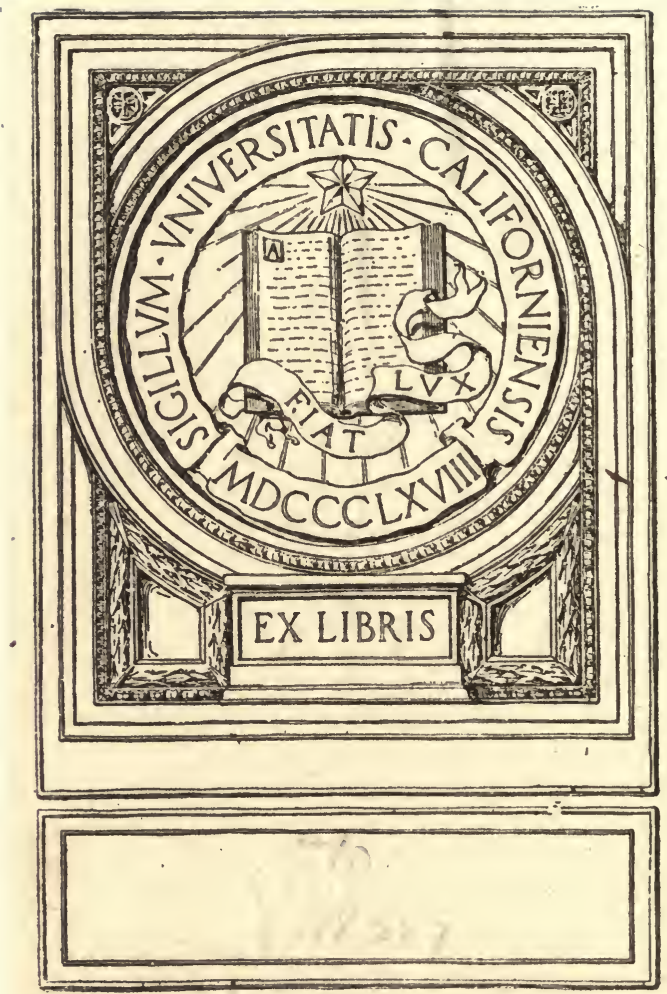






\section{Eggs a Year Per Hen': How to Get Them.}

\section{A Practical Treatise}

ON

Egg Making and Its Conditions AND Profits in Poultry.

BY EDGAR WARREN.

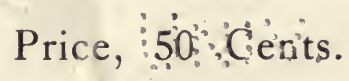

Syracuse, N. Y. CLARENCE C. DE PUY, Publisher. 1912. 


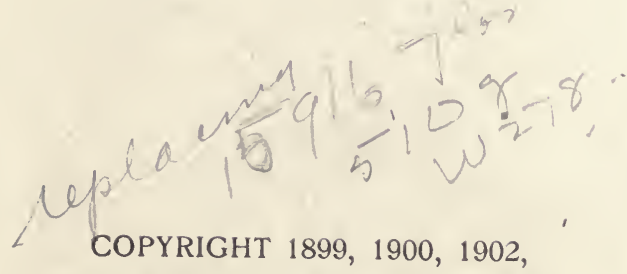

By EDGAR L. WARREN.

COPYRIGHT 1905,

By Clarence C. De PUY.

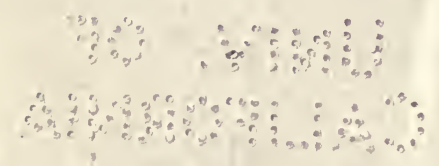




\section{CHAPTER I.}

\section{The Two Hundred Egg Hen.}

We hear a good deal said in these days about the 200 egg hen. Some are disposed to deny her existence, and to class her with such fabulous or semi-fabulous birds as the phoenix and dodo. Others admit that she has appeared in isolated instances, but is by no means common. Others contend that if she should appear in large numbers it would be a misfortune rather than otherwise, for such excessive egg production would weaken her system so that her eggs would not hatch healthy and vigorous chicks; and the $200 \mathrm{egg}$ hen would be in constant danger of extinction from her own success.

One thing is certain, however, the 200 egg hen is no myth. There are many of them scattered about, and the tribe is on the increase. My reputation for truth and veracity is reasonably good; yet I am willing to make oath that I had a flock of fourteen White Wyandottes that from October to October gave me a total of 2,999 eggs, an average of a little better than 214 eggs apiece. There are others who can beat this. Men are already talking of the $250 \mathrm{egg}$ hen, and before we realize it she will be here.

I do not see how a man can draw an arbitrary line, and say how many eggs a hen may or may not lay in a year. The hen in her wild state lays from six to ten; the average farmer's hen not over 100; while on egg farms the average is raised to 150 . But why stop here? There are 365 days in a year; and I do not see why a pullet that is fully matured, that comes from an eggproducing strain, that is properly fed and cared for and kept steadily at work, may not lay at least 200 eggs in that time.

I am prepared to admit that a hen will not lay 200 eggs a year without constant and intelligent care. I am also prepared to admit that in some cases the number of eggs extra a hen will lay where she has this constant and intelligent care will not pay for the time consumed, and that it may be more profitable to get an average of say 150 eggs a year than a larger number. But I believe that in the poultry business, as in every other, it is well to have a high ideal. The man who inscribes on his banner, "Two Hundred Eggs a Year Per Hen," and then comes as near it as he can, will make more money and have more fun than will the man whersent to take what comes along. 
THE HEREDITY OF THE TWO HUNDRED EGG HEN.

When I was a boy a mile in 2:40 was regarded as a great performance for a trotting horse. There were horses that had trotted under $2: 40$, much under, but they were few. I remember it was the custom for us urchins to cry out whenever a man drove by at a slashing gait, "Got it, two-forty!" I am not an old man yet by any means-my wife tells me that I am young-but I have lived to see the trotting record come down and down until it has dropped below the two minute mark. A horse that cannot trot in less than 2:40 is regarded as a good horse for a woman to drive, but out of place on the track.

What has brought the record down and down until men are looking for the two minute horse? Heredity and handling! A trotting horse now has a pedigree as long as a European monarch. The blood of generations of trotters flows in his veins. It may be the ancestral lines converge in the great Messenger himself.

Heredity and handling! These two things are as necessary for the $200 \mathrm{egg}$ hen as for the two minute horse. Men do not gather grapes from thorns nor figs from thistles. The $200 \mathrm{egg}$ hen must be bred to lay. She must come from an egg-producing strain. No matter how scientifically a man may feed or how hygienically he may house, he cannot take a flock of hens of any old breed or no breed and get 200 eggs a year apiece from them. It is impossible. By carefully following the instructions of this book he can largely increase the egg yield of such a flock, but he must not expect to get 200 eggs a year apiece from them. I cannot impress it too strongly upon the reader's mind that if he expects to get 200 eggs a year apiece from his hens he must start in with a great laying strain.

\section{WHAT BREED IS BEST?}

There is an old Latin proverb, De gustibus non est disputandum, which I will take the liberty to translate for the benefit of those who have been out of school for some time. Its meaning is this: In matters of taste there is no argument. This is as true in the poultry business as it is elsewhere. Other things being equal that breed is the best for a man which he likes best. There is no breed that combines all the excellences and has none of the defects. There is no breed that does not have its admirers. In general it may be said that the most profitable breeds are to be found in the Asiatic, American and Mediterranean classes, as follows: In the Asiatic class the 
Light Brahmas, Black Langshans, Buff and Partridge Cochins; in the American class the Barred, Buff and White Plymouth Rocks, all the Wyandottes and the Rhode Island Reds; in the Mediterranean class the Black Minorcas, Brown, White and Buff Leghorns. These are the great money-making varieties. The Asiatics are excellent table fowls and prolific layers of dark brown eggs. They are good sitters and mothers, although somewhat clumsy. They are inclined to be sluggish and readily take on fat. They stand cold well, and make good winter layers. The Mediterraneans are egg machines, turning out great quantities of white-shelled eggs. They do not stand cold as well as the Asiatic and American breeds, and are not as good fowls for the table. The Americans on the whole are the favorites. They are all-round birds, good layers of brown eggs, excellent for the table, gond sitters and mothers. They stand cold well, and are the birds for farmers and breeders. The danger with every breed is that it will get into the hands of the fanciers and be bred for points rather than for utility. Stamina is the important thing, and not the show card. It will be a great day for the poultry business when farmers keep more pure-bred fowls, for then the great standard varieties may be kept up without danger of deterioration.

\section{HOW MANY VARIETIES SHALL I KEEP?}

After studying the matter carefully, I have come to the conclusion that it is better for the average poultryman to confine himself to one variety. He will get better results and make more money if he concentrates his energies than he will if he dissipates them. After a man has made a success with one variety he may perhaps add another, and even a third; but the best poultrymen do not handle many varieties, and some of the most successful confine themselves to one. Where several varieties are kept I would suggest that there be some principle of unity determining the choice. Let the birds all be of one color-say white, black or buff-or let them all be of one family, like the Leghorns, Wyandottes or Plymouth Rocks. Where the fowls are all of one family they will have the same characteristics and respond to the same treatment. In case of an accidental mix-up the damage is reduced to a minimum, for the birds are all of the same size, comb and contour.

\section{HOW MANY RECORDS ARE WRECKED.}

Some time ago I received a letter from a young lady who is an enthusiastic poultrywoman, in which she said that she was 
getting a goodly number of eggs, but that her record was lowered because she had kept over half a dozen hens which had laid well the year before. She said that she knew better, but could not resist the temptation. I mention this case because it is so typical. More egg records are wrecked by keeping old hens in the flock than in any other way! There is always a temptation when a hen has laid well to keep her the second year. This temptation must be resisted if one is in quest of a big egg record. The fact that a hen has laid well for one year since coming to maturity incapacitates her from ever laying so well again. She has drained her system, and requires recuperation before she can lay even moderately. You may set it down as an axiom that it is the pullets that give the big records. If you have in your flock some hens that you desire to keep a second year as a reward for past services, or for breeders and mothers, put them in a pen by themselves and do not look for more than a moderate egg production from them. It is the pullets that lay, and the early-hatched pullets at that. Get out your chickens in March, April or May, according to the breed, if you want winter layers.

\section{WEED OUT THE NON-LAYERS.}

Reports from the Maine Experimental Station where trap nests are used and individual records kept, show that among hens of the same breed and kept under the same conditions there is a great difference in egg production. One Barred Plymouth Rock laid 251 eggs in one year, while another in the same flock laid but eight. A White Wyandotte pullet laid 219 eggs, while another of the same breed laid absolutely none. These figures are most significant, showing as they do the absolute necessity of weeding out the non-producers. Suppose you have two hens in a pen, and one lays 200 eggs a year and the other none. The average for the two is 100 eggs apiece. In other words, the non-layer has reduced the pen record one-half. It costs a dollar a year to feed a hen, and this money is thrown away if the hen does not lay. The one absolutely sure way of identifying the layers and non-layers is by the use of the trap nest; but this takes time, and many do not feel that it pays. Still without the use of the trap nest, by keeping one's eyes and ears open, one can pick out the layers with sufficient accuracy for all practical purposes, as I shall show before I get through. 
THE THREE CONDITIONS OF EGG PRODUCTION.

It was a maxim of Lord Bacon, one of the greatest men that ever lived, that Nature is the great teacher, and that in order to learn we must interrogate Nature. If we study $\mathrm{Na}$ ture with open eyes she will often give us suggestions of great value and fruitfulness. The poultryman must continually go to Nature, the great teacher, and he will not go in vain. In the state of nature in which wild fowls live, or in the state of seminature in which the farmer's fowls are kept, what is the season of egg production? Summer. Why? Because in summer the conditions of egg production are present. What are these conditions? Warmth, proper food and exercise. Reproduce these conditions at any season of the year and the fowl will be likely to lay. The poultryman should keep this fact in mind and govern himself accordingly.

\section{IS THERE AN EGG TYPE?}

Before I pass to the next chapter I wish to take up a subject upon which there is a wide difference of opinion-Is there an egg type? Some of those who ought to know claim there is not. But I am of the opinion that as there is a type of cow that we associate with large production of milk, so there is a type of hen that we may associate with large production of eggs. 'I believe that a hen with a broad breast, a long, deep body and straight underline (the so-called "wedge-shape" fowl) will lay better than one with a narrow breast, a short body and curved underline. The reason is not far to seek. The vital organs are confined within the body, and in a hen with a broad breast and long, deep body there is plenty of room for the organs of assimilation and reproduction; while in a hen with a short, curved body these organs are necessarily constricted. If a hen is to lay well she must eat well, breathe well, and have large ovaries; in other words there must be plenty of room inside for all the great organs to perform their functions. This explains why there is a tendency on the part of the egg-producing breeds to increase in size. 


\section{CHAPTER II.}

\section{The Home of the Two Hundred Egg Hen.}

Much of a man's success or failure in the poultry business will depend upon the location and construction of his plant. Where hens are kept in small numbers and given free range, they do well almost anywhere; but where they are kept in large numbers and in confinement, they must have as favorable conditions as possible or they will prove a source of loss and not of profit to their owner.

The best location for a poultry plant is on sandy soil, where there is a gentle slope to the south or southeast. If there is a wind-break of some kind on the north and northwest the location becomes ideal. Such a location, however, is hard to findnor is it indispensable. Poultry can be kept on almost any soil, provided it is not saturated with water for a considerable portion of the year. Even a clay soil has its advantages; it produces a luxuriant growth of grass which not only provides the fowls with forage, but which also by its roots takes up the excrement which otherwise might contaminate the ground.

Before the poultryman drives a nail or does a stroke of work he should carefully consider the possibilities of his situation, and lay out his prospective plant in his mind. If he is to build largely at once it might pay him to consult an expert. But if he is to build only one small house, he should build it with reference to others that he may put up in future years. So I say, have a plan. The details may be filled in at the poultryman's convenience-or they may never be filled in. But if the man lives and his business grows the time will come when the will thank his stars that he was wise and far-seeing enough to have a plan at the very start, and not have to waste time and money moving buildings about or in tearing them down and replacing them with others.

\section{THE COLONY PLAN.}

There are three methods of keeping hens in large numbers. The first of these is the colony plan. The principle of the colony plan is that of keeping hens in small segregated housestwenty-five to fifty hens in a house. These houses are scattered at regular intervals over the farm, and are visited two or three times a day by an attendant. The hens are given free 
range. It has been found that when houses are one hundred yards apart, or even less, flocks will not mingle, but each flock will keep in the neighborhood of its own house. This plan has its advantages. It is inexpensive. The houses may be of the cheapest kind. No yards are required. The hens at certain seasons of the year pick up a good deal of their living. If the

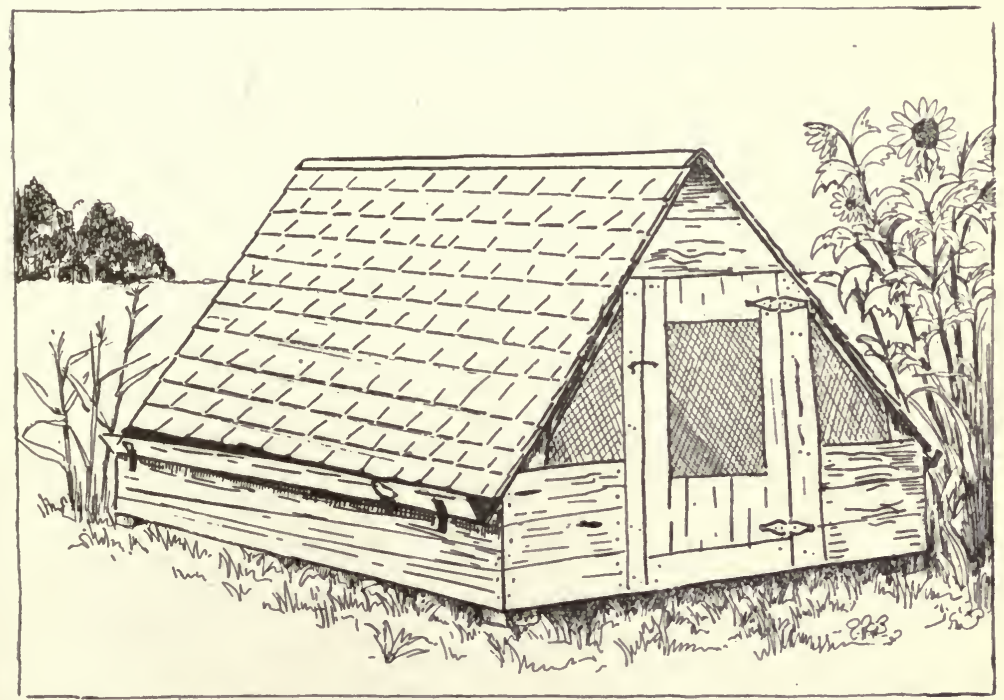

Colony house to accommodate from 12 to 25 fowls. This house is eight feet square on the ground and eight feet from floor to apex of roof. There is no frame, but the roof boards are nailed to the ridzepole and to plank baseboards.

houses are located in an orchard the hens fertilize the ground around the trees and. eat the wormy fruit. No dangerous disease is likely to break out among hens kept in colonies. But on the other hand the plan has serious drawbacks. Even in pleasant weather it requires a good deal of time each day to visit the scattered flocks; but in winter, when a blizzard is raging, to make the rounds of the houses is an experience calculated to make one appreciate the perils and hardships of a Polar expedition. Then, too, these isolated, detached houses are shining marks for thieves; and unless the neighborhood is exceptionally honest, the poultryman may wake up some morning to discover that two or three hundred of his fowls have vanished.

\section{THE COMMUNITY PLAN.}

The second method of keeping hens in large numbers is what I may call the community plan, and is sufficiently described by the name. The majority of large poultry plants in the country are constructed on this plan. The great argu- 
ment in favor of this plan is economy-economy in labor, economy in land. The original cost of a plant on the community plan is somewhat greater than the cost of a plant on the colony plan; but when the plant is erected and equipped the sarving begins. There are, however, some objections to this plan besides the initial cost. It has been found very difficult to keep the houses perfectly dry, where the length exceeds sixty feet. Moisture collects on the walls and roof, and in cold weather congeals, so that in these long houses there is often a coating of frost. In cleaning out the long houses it is somewhat difficult to reach the central compartments, requiring as it does a long walk and the opening and shutting of many doors and gates. Where a virulent disease like cholera or roup breaks out in one compartment, as it sometimes will, it has been found almost impossible to confine it to that compartment-germs traveling in the air, or being conveyed from one pen to another in excrement which may stick to the feet. With the community plan go long, narrow yards or parks, which can be fenced only at considerable cost.

The scratching shed has now become an integral part of many of the long houses. The scratching shed, as its name implies, is a place for exercise under the same roof with the laying room, but more open to the weather. The scratching shed has many enthusiastic advocates who claim that it is indispensable to the health and comfort of the fowls in the winter, and will more than pay for itself in an increased egg output. The claims for the scratching shed house seem so valid. that if I were building a house more than sixty feet in length, I should certainly add scratching sheds.

It is impossible in an article like this to give a plan for a house that will suit every purse and every place. I can only submit a cut of what I consider the best community house I have yet seen, and give a brief description of it. The house is. on the Gardner \& Dunning Poultry Farm, of Auburn, N. Y.

The house shown in the foreground of the view is 180 feet long by 12 wide, and is divided into ten sections, each 18 feet. Each section is in turn divided into a scratching shed of nine feet, and a laying and roosting room of the same length. The house is made of the best material, double boarded with paper between and ceiled overhead at the height of six feet. In each pen is a large window, a small ventilating window into the hallway and a ventilating hole out through the ceiling which draws off the foul air, but forms no draught. 


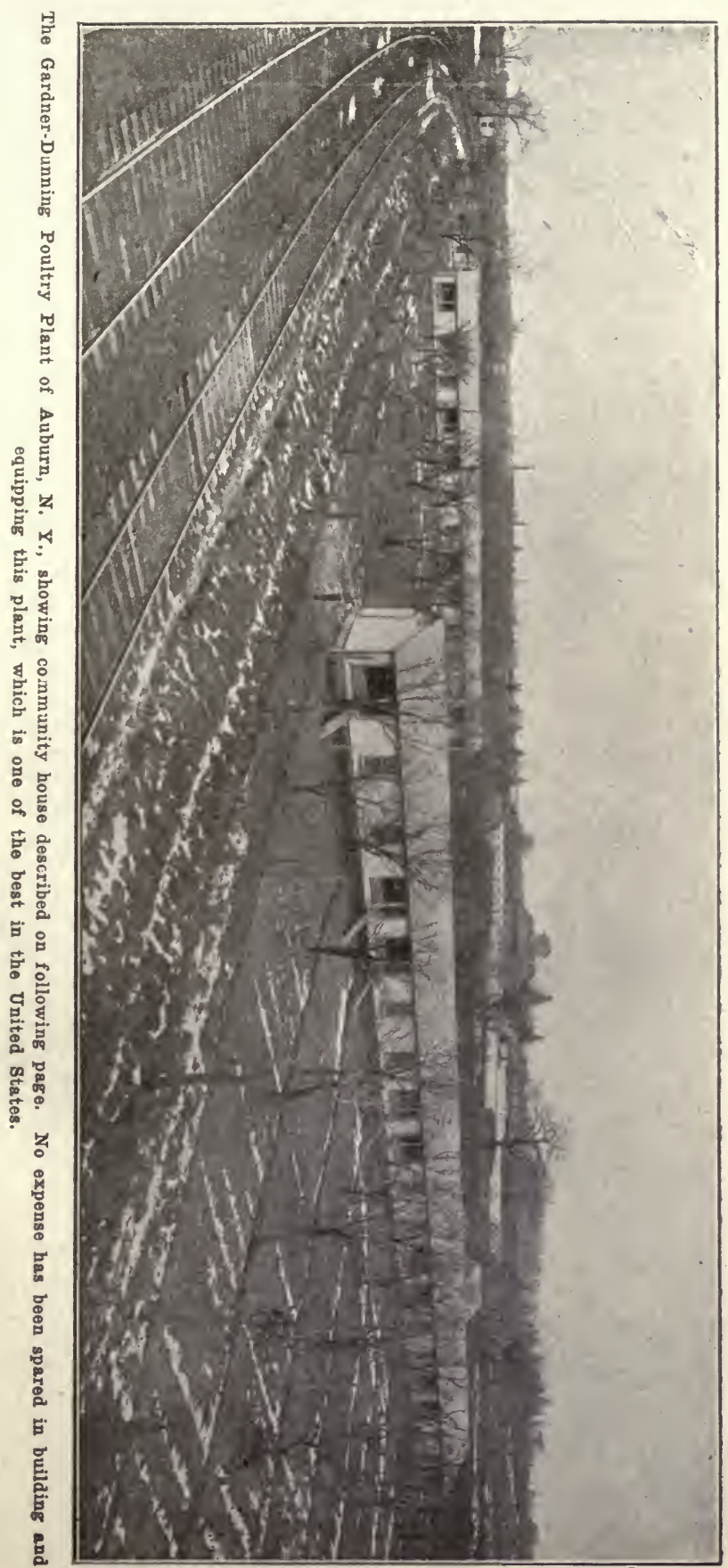


The scratching sheds are open in front, with a canvas which can be let down to keep the snow out. The yards are 150 feet long, with a row of fruit trees in each, and are plowed and sowed each year. At present there are three of these long houses on the plant and more will be added as they are needed.

\section{THE MONTANA EXPERIMENT STATION HOUSE.}

An important and in many. ways desirable variation from the ordinary scratching shed house is the main poultry building in use at the Agricultural Experiment Station at Bozeman, Montana. "The building is 72 feet long and 14 feet wide with a 4-foot passage in the rear. It is divided into pens 12 feet long and 10 feet wide, and is set upon a foundation of stone 18 inches wide and two feet high. The slope of the roof is for the main portion to the south, the ridge coming just above the passage way four feet from the rear wall. This slope of roof is of great advantage since the sun rapidly melts the snow on the southern incline, making it warmer and drier, while on the other side the slope is so steep that the snow does not lodge there.

"The next most important feature is the double floor. The exit from the pens is through the floor into the space underneath the building. This basement has a ground floor, and it is two feet from the ground to the sills. In summer this makes a fine, cool and shady place when doors shown in cut are down and portholes open, while in winter with the doors raised the low sun enables the sunlight to extend more than half of the distance from front to rear, making an ideal place for dusting and scratching. This feature adds greatly to the usefulness of the building, since it so materially increases the floor space without affecting the area of the roof."

\section{THE COLONY-COMMUNITY PLAN.}

The third method of keeping hens in large numbers is, so far as I know, original with me, and may be called the colonycommunity plan. The plan in brief is this: To keep the hens in small detached houses built in streets and situated close to one another, with yards running to the rear instead of the front.

It has always seemed to me a great mistake to run the yards to the front of a hen house instead of to the rear. There are innumerable occasions when the poultryman wishes to visit a pen in the middle of a long house, and in order to do so he must open and shut half a dozen doors to pass along an alley- 


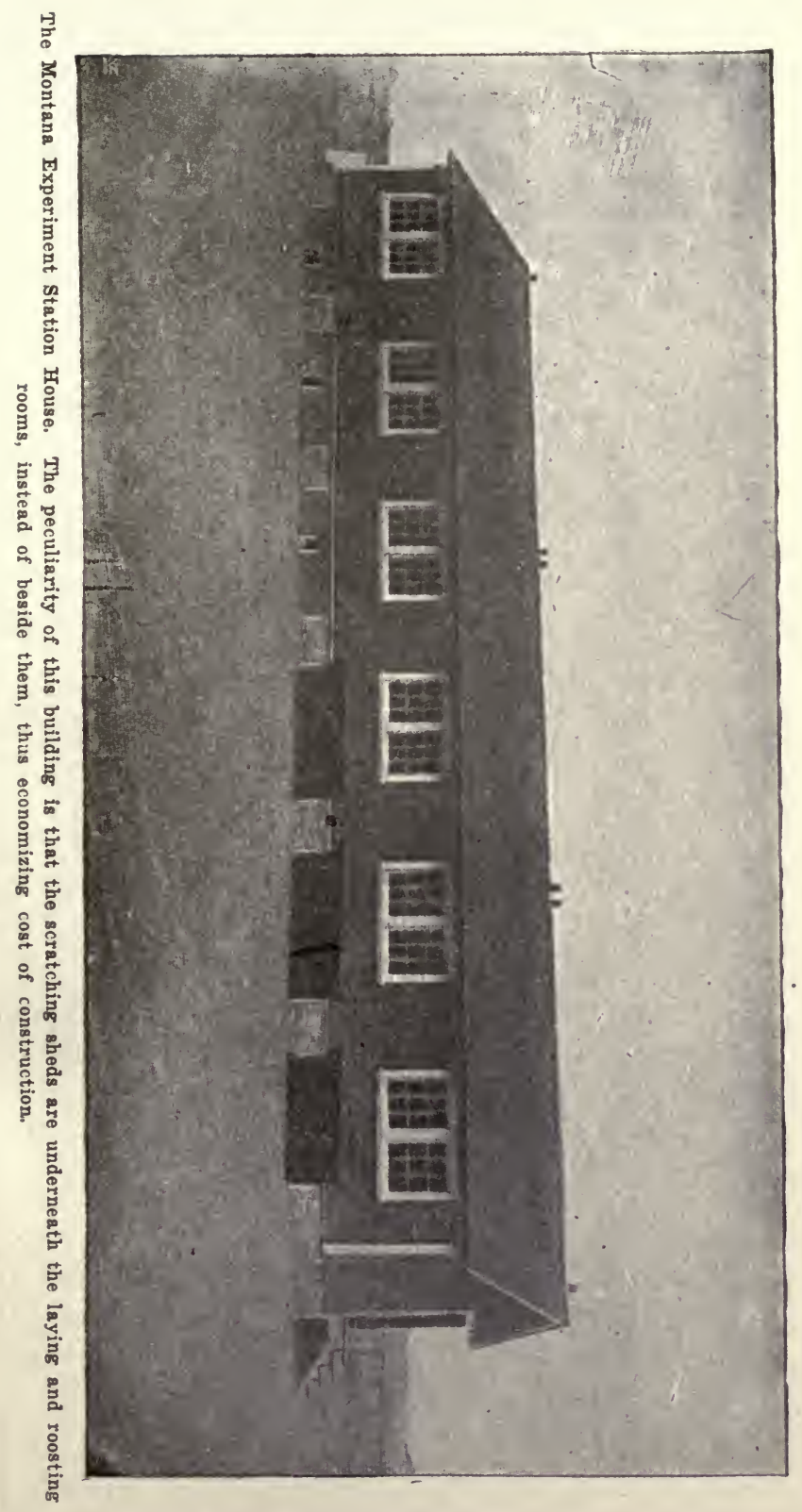


way for fifty or one hundred feet. When he wishes to remove the litter or shovel sand into the middle pens it is necessary to open and shut a number of gates before he can do so. But with the yards in the rear the poultryman can drive along the front of his house and reach the middle pen as easily as he can at the ends.

The houses that I use in the colony-community plan are all alike, and are very simple in construction. Each house is 12 feet long, 7 feet wide, 7 feet high in front and 5 feet high in the rear, and is designed to accommodate 50 brooder chicks, 20

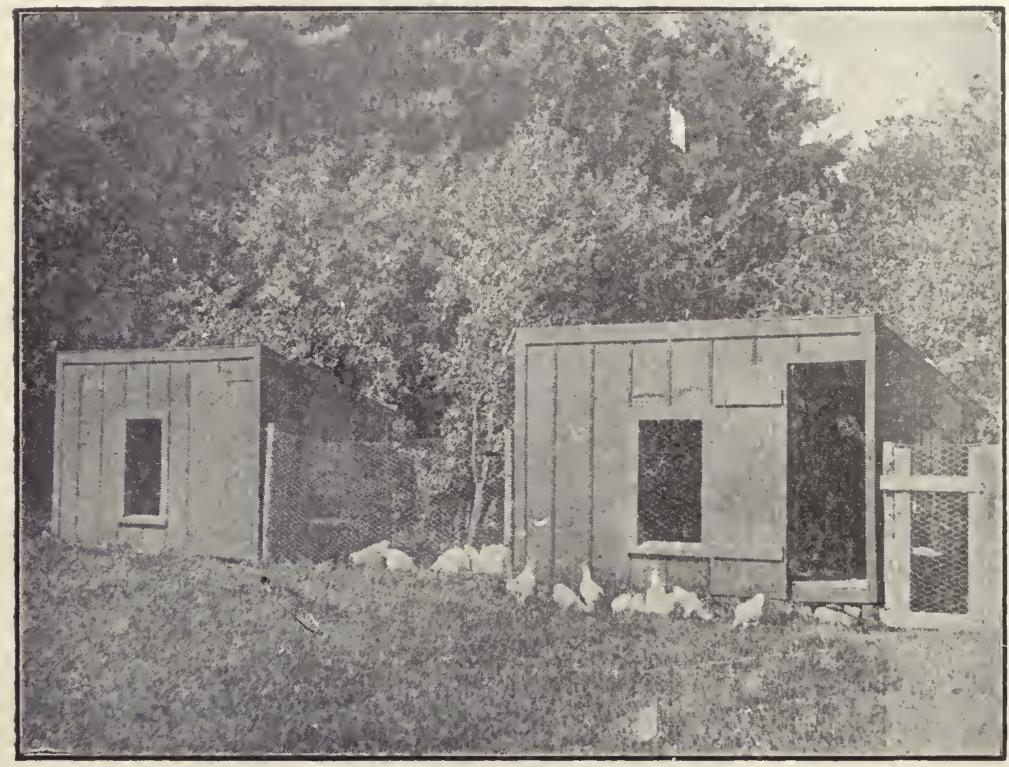

Colony-community houses arranged in streets, with yards running to the rear. head of laying stock, or a breeding pen of one male and twélve females.

The house rests on cedar posts or old railroad ties put in the ground below the frost line and sawed off eight inches above the surface. There are six of these posts, three on each side, and where old railroad ties are used the whole cost of the foundation is 15 cents. On these ties are laid two main sills and four cross sills, each $2 \times 4$ spruce. The plates are $2 \times 4$ stuff, but the other timbers in the frame-posts and rafters-are $2 \times 3$.

After the building is framed the floor is laid. This is double, and between the upper and lower floor Neponset black sheathing is used. The covering to the frame is then put on, and over the boards Neponset black sheathing is tacked. This 
is to be covered with Neponset red paper. All the boards in the frame are hemlock.

The roof is a very important part of a hen house. When the rafters are put on they are sawed off flush with the plate; and when the sides are boarded the boards are brought up'so that they cover the ends of the rafters and also the edge of the roofing boards, making an absolutely tight joint. Neponset black sheathing is then laid over the roof boards, and a double course of shingles laid along the lower edge of the roof. The object of this course of shingles is to throw the water from the

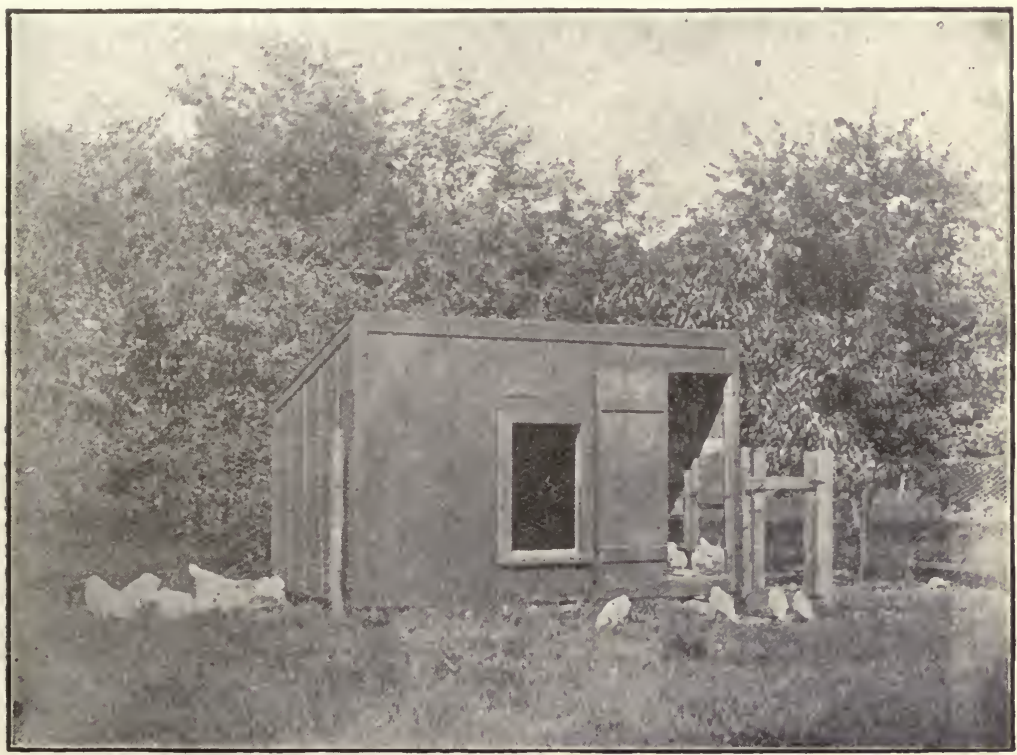

Colony-community house designed to accommodate 50 brooder chicks, 20 head of laying stock, or one male and 12 females.

roof away from the house. The roof is then covered with $\mathrm{Pa}$ roid, carefully put on and allowed to project a few inches at the ends. This flap will eventually be turned in and held in place by the finish.

The house is supposed to face south. There are two windows, one on the south side and one on the east end. There is a door in front, and a panel in the rear which can be raised or lowered at will to let the hens out into the yard. After the house is finished all the outside woodwork receives a coat of dark green paint, which forms an effective contrast with the brick-red of the Neponset paper. Indeed, all who see the house remark how neat and pretty it is. 


\section{INTERIOR CONSTRUC'TION.}

The interior of the house is of the very simplest. I have learned from hard experience to have as little furniture in a hen house as possible, and that many of the things advertised as helps for poultrymen are really hindrances. The house, as I have said, faces the south. The roosts, instead of being in the rear, as is commonly the case, are in the west end, away from all possibility of draughts. The roost platform is two feet and a half above the floor, and is constructed of dry matched pine boards, which I get from old dry goods boxes. The platform, as soon as built, is covered with a coat of hot tar. There are two roosts, or perches, parallel and on the same level. I forgot to say that the roost platform is three feet wide, which enables me to place my perches one foot apart and one foot from the back wall and one foot from the edge of the platform. The perches are of spruce, $2 \times 3$, with the upper end slightly rounded, and set in sockets cut out of boards. They are removable. The perches are also covered with hot tar, as are the sockets in which they are set. Red mites let my houses severely alone.

The materials used in the house are as follows: Hemlock boards, 500 feet; matched pine for doors, trimmings, etc., 60 feet; frame (board measure), 100 feet; windows, Neponset black sheathing, 250 feet; Neponset red rope, 250 feet; Paroid, 100 feet; hardware, etc. The cost of such a house, exclusive of labor, in New Hampshire to-day would be not far from \$20. Two men, working together, can complete the house in two days. Such a house always finds a ready sale, and if the owner wishes to move out of town or go out of the hen business at any time he can sell the house for about half what it cost him.

In case a somewhat larger house is wanted, the dimensions may be enlarged as follows: Length, 14 feet; width, 8 feet; height in front, $7 \mathrm{r} / 2$ feet; height in rear, $5 \mathrm{r} / 2$ feet. This will preserve the proportions and give nearly one-half more floor space.

\section{HOUSE MADE FROM PIANO BOXES.}

Possibly there are some who desire even a cheaper house than the ones I have described. It may be they expect to remain but a short time where they are, or wish a house for young stock, and do not care to invest even $\$ 20$ in a building. To such I would say that a good temporary house can be made from two piano boxes at a cost of about $\$ 3$. The simplest way to make such a house is as follows: On a level place lay down 
two joists eight feet long. Take the boxes and carefully remove the boards on the tallest side. Spike the boxes to the joists so that the open ends will face each other. With the boards you have taken out close up the gap between the boxes on the back

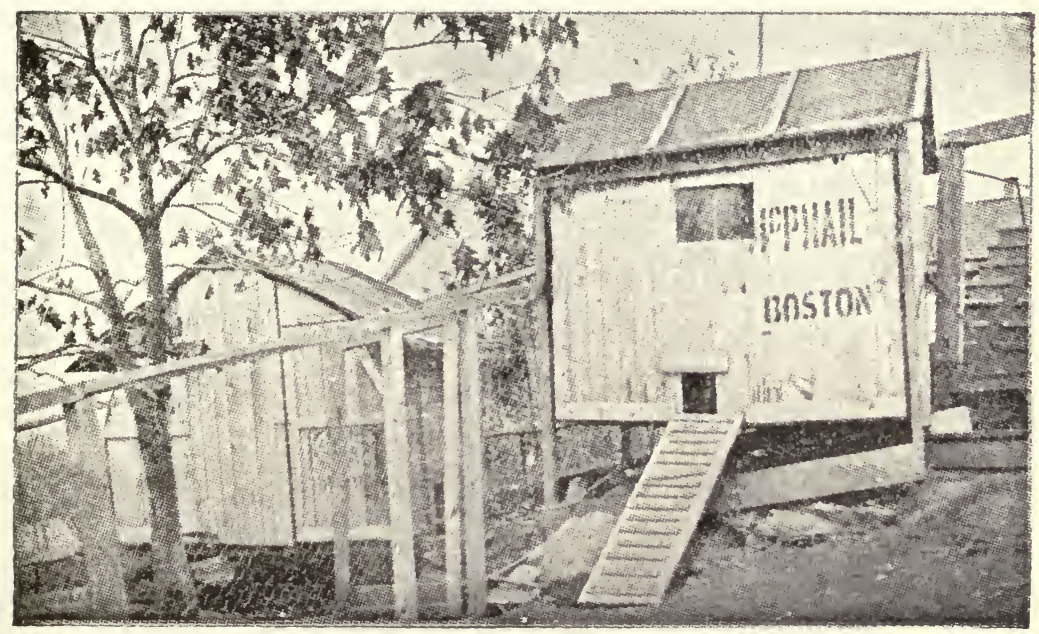

Three Dollar Poultry Houses. Good summer buildings, and in a warm climate suitable for winter.

and roof. . Put a door in front, a pane of glass on either side of the door, or two panes in the door itself, complete laying the floor, put in a roost, cover the building with good roofing paper, and you will have a good poultry house, which is ideal for anyone who desires the largèst return from his investment at a trifling cost. 


\section{CHAPTER III.}

\section{Sanitation as a Factor in Egg Production.}

Sanitation is one of the most important factors in egg production. As blossom and fruit are the culmination of the tree's activities so the egg is the culmination of the activities of the hen. The hen cannot lay heavily unless she is in perfect physical condition. One of the ways in which disease first reveals itself is in the dropping off of the egg product. The poultryman who desires the-largest return from his investment must make a careful study of sanitation.

\section{A SANITARY HOUSE.}

The style of house a man builds will depend something upon his means and personal preferences. There are houses costing thousands of dollars, and there are houses built for less than a dollar a running foot. I have known hens to do well in houses made of piano boxes, costing, when completed, three dollars apiece. But whether the house is cheap or dear, elaborate or simple, it should have, three characteristics:

1. It must be dry. Dampness is fatal to fowls. Roup, rheumatism and kindred evils go with a damp house. The house should always be built in ample season so that it may thoroughly be dried out before winter, and unless the ground on which it stands is as dry as powder it should have a board floor.

2. The house should be warm. Nature has provided the hen with an ample covering of feathers, and she will not freeze even if the temperature falls far below zero. But under such conditions she will lay but few eggs. How can she? All her food goes toward making caloric, and there is no surplus for anything else. In a properly constructed house there is no need for any artificial heat. A house should be built so that in the coldest weather water will not freeze solid in it. If it does a curtain should be provided to drop down behind the hens and shut them in when they are on the roosts.

3. The house should be sunny. Hens love the sun. See them.stand in the path of sunlight on the morning of a clear, bright winter day. The house should face the south or southeast, whenever possible. There should not be too many win- 
dows, for windows let the heat out as they let it in, and the difference in temperature between noon and night is too great.

\section{KEEP THE HOUSE CLEAN.}

Cleanliness is the most important element in sanitation. Disease germs find in filth a congenial soil. The hen house cannot be kept too clean! The room in which hens are confined plays many parts-it is their sleeping room, dining room, workshop, their bath room and water closet. Suppose a large family to be shut up in one room and obliged to use it for every purpose. Do you not see how careful they would have to be to escape disease? It is a wonder to me how hens manage to live through the winter in the majority of houses, to say nothing of laying eggs.

The hen house should have its daily, weekly, monthly and yearly cleaning. The windows should be opened in the middle of the day for two or three hours on every day in winter when the sun is shining. The droppings under the roots should be removed every morning! When poultrymen realiże that poultry manure is a virulent poison and should not be allowed to pollute the houses or the yards where the hens are kept, they will make a great step toward success. It takes but a few minutes to a house to remove the droppings, and the gain in looks and in wholesomeness is worth the cost. After the droppings are removed the dropping board should be sprinkled lightly with earth, coal ashes or land plaster.

Once a week, summer or winter, the drinking vessels should be scalded out, and once a week in winter the litter should be shaken up, and if you have a board floor, the dust and dirt that settles to the bottom should be removed. If the floor is of earth the surface droppings should be taken out and the earth raked up.

Once a month the cleaning should be more thorough. The litter should be renewed, and the floor swept. The roosts should be kerosened and in summer the walls around the roosts sprayed with kerosene or with a kerosene emulsion. Nest boxes should be emptied, painted with a good lice killer, and when dried out filled about one-third full of dry planer shavings. The dust box should receive attention.

The annual cleaning is still more radical. On some sunny day in autumn-the earlier the better-shut the hens out in their yards and begin work upon their quarters. Everything movable in the house should be taken outside. Sweep the dust 
and cobwebs off the walls, windows and ceiling. Sweep the floor, if you have one. The walls should then receive a generous coat of hot whitewash, put on with a spray pump to save time. A good receipt for whitewash is as follows: Take a sufficient quantity of lime, slack it slowly and wet enough to make into a thick putty. Let it stand in this shape a few hours or a few days, and then reduce it with water to the thickness desired. Add one pint of crude carbolic acid to every 12-quart pailful, and you will have a combination that will be death to lice. Sprinkle the floor with napcreol or some other disinfectant, kerosene the roosts, paint the nest boxes with some good lice killer, cover the dropping board with a coat of hot tar-in short, give the house a thorough cleaning.

\section{LICE AND RED MITES.}

Relentless and persistent war must be waged against lice and red mites. The poultryman who keeps his house in the sanitary condition I have described is apt to think that the battle is won, that there is nothing more to do. Such is not the case. The foe is hiding; it is not destroyed. There comes a falling off in egg production, and the poultryman wonders what is the cause. "Lice," says a too candid friend. The poultryman waxes. indignant. "I'll give you a dollar apiece for every louse you find on my hens!" he exclaims. The friend takes a hen off the nest, and holds her up toward the light. "Pull apart the fluff around the vent," he commands. The poultryman does so, and, lo! a covey of lice may be seen cutting to cover in the dense jungle of soft feathers.

Where a big record is desired the hens must not be left to rid themselves of lice by their own efforts, but must be dusted from time to time. The poultryman can make his own insect powder cheaper than he can buy it, but where only a few hens are kept it will not pay him to do so. Lambert's "Death to Lice" and Cyphers Lice Powder are standard preparations. If the poultryman wishes to make his own powder here are two formulas that may be depended upon:

1. Take one pint of slacked lime and stir into it one ounce liquid carbolic acid. Add to this mixture three pounds finely ground tobacco and mix thoroughly. This powder dusted wherever lice are will kill them. 2. Take five pounds strong tobacco dust, one pound airslacked lime, one-half pound naphthalene-mix well together. This is sure death to hen lice, plant lice, lice on cattle, sheep ticks, bedbugs, ants, moths, etc. 
Lice paint is a liquid preparation, and is used for painting roosts, nests, etc.

The fumes penetrate the feathers of the bird and kill the lice. Lee's Lice Killer and Cyphers Surekil Lice Paint are highly recommended. A good lice paint is made by dissolving one pound naphthalene flakes in one gallon kerosene oil.

Red mites make their homes on the underside of the roosts and in cracks and crevices adjacent. They are quiet by day, but by night come forth to suck the life blood of their victims. The kerosene treatment, which I have already described, is sure death to red mites, and it is folly not to exterminate them.

\section{TO RID A HOUSE OF VERMIN.}

Sometimes through carelessness or neglect a house becomes infested with vermin, and then radical measures are necessary. In the first place the house should be thoroughly fumigated. Close every door and window, and see that there are no cracks or apertures to admit air. Burn a pound of sulphur for every 100 square feet of floor space in the house, thus: a house 10x10 will require one pound of sulphur; one $20 \times 10$ two pounds; one $30 \times 10$ three pounds, and so on. The sulphur must be burned in iron vessels, which must be set on gravel or sand, so that there can be no danger from fire. Into each vessel put a handful of carpenter's shaving, saturated with kerosene, and upon these sprinkle the sulphur. Place the vessels in position, apply a match to the shavings, and hastily leave the house, closing the door behind you. Do not open the house again for five hours, when every door and window should be thrown wide open. In case you feel any anxiety about fire, you can look in through a window once in a while to see that everything is going well.

After the fumes of sulphur have been driven out, with a hand sprayer, go through the house, sending a spray of kerosene everywhere. These sprayers can be bought for half a dollar each, will last for years, and are simply invaluable. All the time you have been at work the hens have been in the yard outside, without food, and are now anxious to return to their home. Let them in, one by one, and as each enters catch her and dust her well with some good insecticide.

\section{GIVE THE HENS PLENTY OF ROOM.}

There is a snare spread for beginners in the poultry business which catches nearly all; it is to crowd the birds. The 


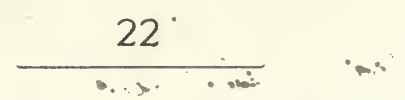

prospective poultryman has a small flock and they have laid well. He begins to reason like this: "I have kept twelve hens in the pen the past year and they have netted me $\$ 2.00$ apiece. All I have to do to increase my income is to increase the number of my birds. If twelve hens have paid $\$ 24$, fifty hens will pay me $\$ 100$." This seems logical, and the prospective poultryman goes to work and puts in fifty birds, only to find at the end of the year that the fifty birds have not paid him so well as the twelve did. They have laid no more eggs, and sickness has been rife among them. More men lose money and retire from the poultry business in disgust from losses brought about by putting too many birds into one pen than from any other cause.

The farmer would not think of putting two cows in one stall. He would not plant his potatoes in rows one foot apart. He would not shut up his family in one room. Why should he not display the same good sense in dealing with his fowls? Experience has shown that 10 square feet of floor space is about the amount needed by each hen if she is to do her best. Where the house is kept perfectly clean, and where the hens have a chance to get out of doors every pleasant day, they can get along with a somewhat smaller space. But for the best results in egg producing there must be plenty of room. The year I made the phenomenal record with my White Wyandottes-214 eggs apiece from October to October-I knocked out the partitions between two pens and gave the flock double room.

\section{DUST BATH.}

Provide your hens with a dust bath. They will spend many happy hours wallowing in the warm earth and will keep themselves reasonably free from lice. But do not trust to the dust bath entirely, for in the dead of winter the bath is often so cold that the biddies will not use it, and then lice will get in their work. Soil out of the garden, sifted through a common coal sieve, makes the best material for a dust bath that I know anything about. Next to this I rank coal ashes. The bath tub may be a sugar barrel, sawed off about a foot from the bottom and set in a sunny place, or one of those shallow square boxes that cereal foods come in, which may generally be obtained of the grocer for the asking.

\section{EXERCISE.}

Hens need a reasonable amount of exercise. They do not need to be kept on the jump from morning until night, but they 
do need enough exercise to keep them in good trim. Where hens have free range they will attend to the matter of exercise themselves-although a hen having free range knows enough not to work when it is very hot or very cold. But when in confinement exercise must be provided for them. The floor of the hen house, or scratching shed, should be kept carpeted with six inches of litter in winter, and the fowls should be made to work for all the grain they eat. This litter, as I have already said, should be frequently shaken up and occasionally renewed. Straw, fresh hay and dead leaves make the best litter. Dry planer shavings are good if they are not allowed to become too fine.

\section{THE POULTRY YARD.}

In summer the hens should be out in their yards. The yard does not need to be very large. Indeed, unless the yard is large enough to grow all the green stuff that is needed for forage. a small yard is better than a large one, for it is more likely to be kept clean. Much money is spent each year for wire netting and foundation boards for fences that could be laid out to much better advantage in some other way. There should be shade of some kind in the yard. If the yard is small it should be raked and swept every week and the surface droppings removed. It should be spaded up from time to time. In the spring the surface soil to the depth of three or four inches should be removed and spread on the garden and replaced with fresh earth. If this is done there is much less danger with a small yard than with a big one that is never cleaned.

\section{GRIT, CHARCOAL AND OYSTER SHELLS.}

Nature has not provided fowls with teeth, and consequently they cannot masticate their food as can the higher animals. The food passes from the crop into the gizzard, where it is prepared for the intestines by trituration; that is, as the food passes through the gizzard it is triturated, or ground up, by the little flinty particles which line that member. Unless the fowl is well supplied with grit the food passes into the intestines improperly prepared, and the result is indigestion. It is a great mistake not to keep the fowls well supplied with grit. Charcoal is an alterative tonic, and should be before the hens all the time. Oyster shells are necessary to supply the lime needed for the egg shells, and nothing can take their place. 
DRINKING WATER.

Pure drinking water is as necessary to the health and comfort of fowls as it is to the health and comfort of human beings, and should be supplied in abundance. The water dishes should be scalded out from time to time, and if a few drops of carbolic acid are added to the water with which they are scalded so much the better. Have your water dish as simple as possible. There is nothing better than a two-quart measure, made of galvanized iron, set on a little shelf by the door of the hen house and six inches from the floor.

\section{SANITATION IN SUMMER.}

It has been my observation that hens that are kept shut up in houses and yards suffer more from lack of sanitation in summer than in winter. There are a hundred directions printed for making the house warm to one for making it cool. And yet anyone who has watched a hen on a hot day in mid-summer, with mouth wide open and wings outspread, must realize that the poor creature is far from comfortable. Houses built on the colony-community plan, such as I have already described, are ideal houses for summer as well as for winter, as there is a window in the front and on the end. As soon as warm weather comes I take out both windows, letting the air circulate freely through the house. Poultry wire tacked on the outside of the swindow frame keeps the biddies in and the. "varmints" out. 


\section{CHAPTER IV.}

\section{Feeding for Two Hundred Eggs a Year.}

We now have our hens in a dry, warm, sunny and sanitary house, have supplied them with facilities for keeping clean, and, of course, want them to lay. What shall we feed and how much? This is an important question, for unless a hen is supplied with material for egg production she cannot lay. She can no more produce eggs without the proper food than a factory can turn out the finished product without raw materials. What shall we feed and how much shall we feed, therefore?

Let us again follow Lord Bacon's advice and interrogate Nature. Suppose we take a hen as she comes up to the house at the close of a long day in summer from foraging in the fields, kill her, take out her crop and analyze its contents. If we do so it is obvious that we shall obtain at least a part of the information we are after, for a hen lays in summer or not at all.

What do we find as the result of our analysis? The crop we are dissecting has about as many articles in it as the average small boy's pocket, and they are equally miscellaneous. We find grains of corn that the hen has picked up about the barn, pieces of bread and table waste that she has found under the sink spout, clover leaves and tips of grass blades, bugs, worms and a mass of matter that we cannot resolve into the original elements. The first thing that impresses us as the result of our analysis is that the hen seeks variety. this mass of miscellaneous matter that we found in the hen's crop can be arranged in three divisions: First, Grain. Second, Green food and vegetables. Third, Animal food-in the form of bugs, worms, and so forth. The conclusion is irresistille, that these three elements must be combined if we would have a perfect ration.

How shall we combine them? The answer is not so difficult as one would at first suppose. There are many ways. The hen makes a new combination every day. Perhaps the ideal way is to have no stereotyped method, but to study variety. If we combine grain, green food and meat in the daily ration, the hen can hardly fail to respond with a goodly output of eggs. 


\section{FEEDING FOR EGGS: HOW MUCH?}

The problem, as every poultryman knows, is not what to feed, but how much. If you do not believe this write to the editor of your favorite poultry paper and ask him how much food you shall give a flock of 15 hens, and see what he will say. It takes a great deal of skill to steer between overfeeding on the one hand and underfeeding on the other. I believe, however. that there is a.scientific principle underlying the matter, and think that after a great deal of study and experimentation I have discovered the principle.

In order to determine how much we should feed we must again interrogate Nature. Before we began to dissect the crop of the hen we had killed, suppose we had put it on the scales. to ascertain its weight. If the hen from which the crop was takken was of an American breed, if she had been running in the fields all day and just before she had been killed had been given all the corn that she would eat, her crop with its contents would not weigh far from six ounces. Allowing that two ounces of food have passed into the intestines, it will be seen that when a hen is on the range, supplied with abundance of food, she will consume about eight ounces of food in the course of twenty-four hours. It would seem, therefore, that this is about the amount a hen needs to supply all the demands of her system and leave a margin for egg production. But before we settle down to this conclusion there are some things to be taken into consideration. On the range the hen has had plenty of exercise, and needs more food to supply the tissue lost than when in confinement. On the range food is more bulky and less nutritious than the food the hen receives in her pen. It contains a larger proportion of grass and vegetables. It is probable that in the pen, where the hen does not exercise so freely as she does on the range and where her food is more concentrated, she does not need so much food by one-fourth as she does when at liberty. Six ounces of food a day ought, therefore, to be ample to supply all the needs of a hen in confinement.

Six ounces of food a day for a hen weighing six pounds seems at first sight an enormous quantity. In the same ratio a man weighing 160 pounds would consume 10 pounds of food every twenty-four hours. But before we dismiss the matter as absurd let us consider a moment. The hen's food is not so concentrated as the man's. It contains far less nutriment in proportion to bulk. A considerable proportion of it will be 
voided in the form of excrement. Then the hen has a task toperform such as is imposed upon few other creatures. She is expected to lay an egg weighing not less than two ounces; and an egg, as everyone knows, is one of the richest of food products. Deduct from the six ounces of food two ounces for waste and two ounces for egg production, and it will be seen that only two ounces are left to repair the tissues and maintain the temperature of the body. The laying hen needs a generous diet, and those doctrinaires who advocate keeping her in a state of semi-starvation have not support in reason for their theory.

\section{FEEDING FOR EGGS: WINTER ME'THOD.}

Having given my readers the principles that apply to feeding, I propose now to tell them how I put these principles intopractice. I desire to state here that I have no patent methods. I aim to apply common sense to the problem of egg production, as I do other things; but I do not claim to have a monopoly of wisdom. There are doubtless other methods as good as mine. As I said in a preceding section, there are many possible combinations that will produce good results. I give you mine, and leave you to adopt it or not as you think best.

From October to May I feed as follows: A mash the first thing in the morning. The mash is made as I am about to describe. Into an iron kettle holding 12 quarts I put two quarts. (dry measure) cut clover, two quarts mixed feed or wheat bran, two quarts corn meal, one quart green ground bone or beef scraps, and one quart table scraps. The ingredients are thoroughly mixed together. I then take the kettle into the house and set it on the range, where the meal can become warm. I next stir in a heaping teaspoonful of salt, and in the coldest weather sprinkle in a little black pepper. Boiling water is then added to the mash in just sufficient quantity to moisten every particle and yet not have it sticky and sloppy. I consider the mash just right to feed when I can take some up in my hand and have it feel pleasantly warm (not hot), and dry enough so that it will not adhere to the palm or fingers. Some advocate dry feeding. I have no doubt the food is just as nourishing without the water, and after they become accustomed to it (or starved into it) the hens will eat it readily enough; but before the food can be digested it must be moistened, and I think it better and safer to moisten it for the birds myself than to allow them to do so. I do not believe 
the bird can moisten a large handful of dry mixture after it enters the crop so evenly as I can before it goes there. Then if the mash is about the temperature of the bird's body when it is fed (or, on cold mornings, a little higher) she will not have to use up her heat in raising it to that temperature.

\section{FEED ALL THE HENS WILL EAT UP CLEAN.}

I feed all the mash the hens will eat up clean in a reasonable time-say from 15 minutes to half an hour. Then I go through the pens and empty what is left (if anything) back into the kettle to be fed the next day. At 11 o'clock I make a round of the pens to collect the eggs and look after the birds. On this trip I take with me green food of some sort-mangel worzels, cabbages, apples or onions-and leave in each pen the amount that experience has shown me the birds will eat up clean. About 2 o'clock in the afternoon I make the round of the pens again. I have told you that in each pen I keep a male and 12 females, and on this trip in the early afternoon I throw down in the deep litter one quart (dry measure) of grain of some kind. The three grains I feed are wheat, cracked corn and oats. I study to give variety. On a mild afternoon I feed all oats or all wheat, on a moderately cold afternoon, about half cracked corn and about half wheat or oats, and on a very cold afternoon, cracked corn alone. When I get home from making pastoral calls it is generally dusk and the hens have gone to roost. Before supper I go through each pen to see that the birds are all right for the night. I empty the water dishes, collect any eggs that may be in the nests, pause a moment in each house to see that the birds are breathing right (no colds nor bronchitis) and occasionally feel of the crops to see if I am feeding enough. If the crop is comfortably full-neither distended on the one hand nor nearly empty on the other-I conclude that the grain ration is about right so far as quantity is concerned.

\section{STUDY VARIE'TY.}

I have given the ingredients of my standard morning mash, but I vary these ingredients from time to time. I don't want the same thing for breakfast every morning, and I don't believe my birds do. About twice a week I substitute gluten meal or linseed meal for green ground bone or meat scraps; and once in a while I give a breakfast of scalded oats-the oats scalded 
the night before and allowed to stand on the back of the stove where they will be warm and nice in the morning. Occasionally I give a breakfast made up of three parts by bulk of Biles' Fourex* and one part by bulk of corn meal. When I have plenty of small potatoes I make up a dish composd of boiled mashed potatoes, green ground bone and mixed feed or bran, which the fowls eat with avidity. I put in about four quarts potatoes, two quarts green ground bone and two quarts mixed feed or bran-season and serve hot. The table scraps, which I feed every morning, add variety to my standard ration.

*Biles Fonrex ( $\mathrm{xxxX}$ ) is a by-proluct from distlliers' grains. Very rich in fat and protein. A valuable new food, when mixed with one-third its bulk of corn meal.

\section{FEEDING FOR EGGS-SUMMER ME'THOD.}

My method of feeding in summer is substantially the same as it is in winter, except that corn is struck entirely off my list and wheat and oats made to take its place. In summer, too, I give my hens grass and weeds from the garden for green food, instead of mangels, cabbages, apples and onions. We are fortunate here in Hampton in having close at hand an inexhaustible supply of food not usually found. Every northeast storm washes up on the beach tons and tons of seaweed, which may be had for the hauling. A load of seaweed dumped into a yard in summer will breed millions of small white worms, which the fowls eat greedily. These worms, or maggots, are said to be better for the hens than wheat, and certainly form a very cheap addition to the daily bill of fare.

\section{FEEDING FOR EGGS-CAUTION.}

In what goes before I have given my method of feeding but this method will need to be adapted to individual cases. No hard and fast rule can be laid down. The poultryman must study his flock, and learn by experience-he must mix brains with his mash. The large criticism that will be made is that I feed too heavy and do not make my birds exercise enough. Bear in mind, however, that I have been talking about laying stock. Birds that are kept over for breeding are fed the same things that I feed my laying stock, but are not fed so much and are made to exercise more. In one case I am after eggs and a good many of them; in the other, I am after fertile eggs-that will hatch strong chicks. If you notice that your birds are becoming fat and lazy, drop an occasional soft-shelled egg, and 
that their combs instead of being a healthy red are a dull purple, reduce the ration at once and set the birds to work-otherwise you will have dead hens on your hands. About the time of feeding the mash, it don't make a cent's worth of difference whether you feed morning, noon or night, so long as you feed enough and feed the right things.

\section{THE GOLDEN RULE FOR FEEDING.}

Give the hen a sufficient variety and quantity to meet all the needs of her system and leave a margin for egg production. A warm mash in the morning, all she will eat with good relish in fifteen minutes to half an hour. Enough grain during the day so that she will go to roost with a crop moderately full, neither distended on the one hand nor nearly empty on the other. Green food, either in mash or separately. More heating food in winter and more of it than in summer. In general, it may be said that one ounce of food for each pound she weighs is about right for the average hen.

\section{HOW SOME SUCCESSFUL MEN FEED.}

Mr. B. F. Dunlap, West Salisbury, N. H.-One of the most remarkable poultry men that $I$ know anything about is $\mathrm{Mr}$. B. F. Dunlap of West Salisbury, N. H., who keeps from 450 to 500 head of laying stock (White Wyandottes and Rhode Island Reds) and clears up a profit of $\$ 1,000$ yearly. Mr. Dunlap lives five miles from the nearest railroad, and makes his profits from eggs, which he markets in Boston.

"Every day something different," is the principle he goes on, as expressed in his own words. He has four combinations, which he names from the leading articles in each: Boiled potatoes, waste bread, clover hay, whole oats. The four combinations are as follows, enough kettlesful being mixed up to feed the whole flock:

1. Boiled potatoes, soaked over night, 8 quarts; gluten, soaked over night, 3 quarts. In the morning add mixed feed, 2 quarts; corn and oats, ground and mixed together, 2 quarts.

2 Waste bread, soaked over night, 8 quarts; beef scraps, 2 quarts; corn and oats, 2 quarts.

3. Clover hay, soaked over night. In the morning add 2 quarts flour middlings, 2 quarts boiled beef and bone, 2 quarts corn and oats.

4. Whole oats, soaked over night, 8 quarts; gluten, soaked 
over night, 4 quarts. In the morning add 2 quarts shorts, 1 quart beef and bone, 2 quarts corn and oats.

The mash is fed in the morning, and the hens are given all they will eat up clean in ten minutes. The second and last meal comes at noon, and is grain of some kind.

The day Mr. Dunlap feeds boiled potatoes the hens have wheat. The day he feeds waste bread they have wheat or cracked corn. The day he feeds clover hay they have cracked corn. And the day he feeds oats and gluten they have cracked corn or buckwheat. The grain is thrown into the sand and litter in each pen, and the hens have to scratch for it. Mr. Dunlap does not give the hens all the grain they can eat, but as much as they can digest and come to breakfast the next morning with an empty crop and a good appetite. Whole turnips are kept in the pens all the time, so that the hens can get a taste of green food when they want it.

Mr. G. M. Gowell of the Maine Experiment Station is doing some excellent work with hens. Mr. Gowell is the originator of the trap nest described in this book, and keeps individual records. He breeds White Wyandottes and Barred Plymouth Rocks, and long ago found the $200 \mathrm{egg}$ hen. He feeds as follows :

Twenty pullets and two cockerels are kept in each lot.

Each pen of twenty-two receives one pint of wheat, in the deep litter early in the morning. At 9:30 A. M. one-half pint of oats is fed to them in the same way. At 1 P. M. one-half pint of cracked corn is given in the litter as before. At $3 \mathrm{P}$. M. in winter and $4 \mathrm{P}$. M. in the summer they are given all the mash they will eat up clean in half an hour.

The mash is made of the following mixture of meals: 200 pounds wheat bran, 100 pounds corn meal, 100 pounds wheat middlings, 100 pounds linseed meal, 100 pounds meat meal or fine meat scraps. Part of the year the linseed meal is omitted, and the amount of meat meal doubled. The mash contains onefourth of its bulk of clover leaves and heads, secured from the feeding floor in the cattle barn. The clover is thoroughly soaked with hot water. The mash is made quite dry. Cracked bone, oyster shells, clean grit and water are at all times before them. Two large mangels are fed to the birds in each pen daily in winter, and green food in plenty in summer. 
C. Bricault, M. D. V., of Andover, Mass., is another man. who has succeeded in obtaining the 200-egg hen-some of his. White Wyandottes having considerably exceeded this figure. Dr. Bricault relies more upon inheritance than upon any special bill of fare in getting the 200-egg hen, but his method of feeding, as given in his own words, is excellent.

"Morning-One of the following grains is scattered in the litter: oats, wheat, corn, barley, about one handful to two. hens. We then water the hens, giving warmed water on very cold days, that is, water with the chill taken off.

"Noon-Grain as in the morning, but less, about one handfull to three hens. We feed a different grain at every meal. At. this meal we give the green food of the day (cabbage one day, beets the next, scalded clover or whatever we have on hand), but they get green food every day. Sometimes we give a feed. of green cut bone as a variety in place of grain, but we do not feed cut bone regularly.

"Night-Our mash is fed at night, and we give the hens all they will eat. We make the mash as follows : bran, corn meal, ground oats, equal parts by bulk, well mixed together. These meals are put in the trough with enough boiling water to make the mass 'wet dry,' and covered over with a bag and left to cook in their own heat; when cool it is fed. We feed the mash every second day. We feed it in long troughs, and give all they will, eat up clean in half an hour. The days on which the mash is omitted we give one of the above-mentioned grains-one handful to each hen.

"We also keep a small piece of rock salt in each pen for the hens to pick at. This can be placed in a slatted box, with the slats about two inches apart.

"We believe in regularity in feeding and practice it.

"A self-feeding trough is placed in every pen, divided into three compartments; in one there is grit, in another oyster shells; the third contains a mixture of meat and the ground grains used in the mash, half meat and half grain. This last makes a good mixture to serve as lunch between meals.

"After the hens have gone to roost at night we scatter the morning feed in the litter so the hens can go to scratching as soon as they come off the roost in the morning."

FEEDING FOR EGGS: A WOMAN'S WAY.

"In the morning $\dot{I}$ feed a mash made of about two parts bran to one part ground oats. For every 50 hens I put in two quarts, good measure, of green ground bone; also some vegeta-- 
bles, well cooked and mashed. This latter I vary as much as possible, using water in which vegetables have been cooked to moisten the mash, providing it is not so strongly flavored as to be disagreeable to the hens, as sometimes happens if turnips. have been cooked in it. The proportion of vegetable matter given to hens in winter is much smaller than that given in summer, and also smaller than the other ingredients in the mash. In summer cut grass or clover and vegetable tops are substituted for the roots given in winter and are fed separately whenever convenient. Dried beef scraps are substituted in summer for the ground bone in winter and are fed in smaller quantities, perhaps half the amount. I season with salt rather less than I would for my family. I never use pepper, but occasionally ginger. When using pepper and seasoning highly with salt, I have always had more or less hens die of liver trouble in spring. My mash is always thoroughly scalded and frequently well cooked, as in winter I often mix it the night before and let it remain in the oven over night. Animal meal I consider a cheap food which will make hens lay; but I cannot use it, even in much smaller quantities than the rule, on account of its laxative qualities.

"My hens always have warm water in clean drinking vessels in winter and cool water in summer.

"The second and last feed comes after dinner, when I hoe or rake into the litter on the hen house floor two parts whole oats to one part wheat. The litter is six or eight inches deep, and the feed is given generously enough to make them feel rewarded for scratching up to the next afternoon.

"Oyster shells I prefer to throw in fresh every day, especially in the latter part of the winter, when they get too busy laying to eat the proper amount of lime.

"A neighbor adopted my way of feeding, but with pullets bought of me failed to get like results. I attribute the failure to the fact that he was afraid of wasting feed, and if he could possibly find a grain would not feed more. In the morning I feed all the hens will eat with a relish.-Miss L. M. S., Auburn, Me. 


\section{CHAPTER V.}

\section{Foods and Food Values.}

Readers of the poultry and agricultural press are continually coming across expressions, the meaning of which they but dimly comprehend. They read of "narrow" and "wide" rations, "proteids" and "carbohydrates," "concentrates" and "coarse foods." All this in most cases is so much Greek. I have talked with many intelligent poultry keepers, but have rarely found one who could tell why he fed as he did apart from the fact that his ration had justified itself in experience. And yet a little knowledge of the elementary principle of scientific feeding may be of great value. It will enable a man to feed more economically, as he can often substitute for a highpriced food one much lower in price, and also to feed so that he can secure the results he is after without loss of time or waste in any way. It is my purpose in this chapter to make the matter of foods and feeding so simple that anyone can understand it.

\section{PROTEIDS-THINGS THAT BUILD UP.}

The food that is eaten has three functions to perform. The first is to build up. In the animal body a process of waste and repair is continually going on. Old tissues are breaking down and being replaced by new ones. It is evident that if an exact balance is to be preserved considerable food must be eaten. But besides this process of waste and repair another process may be going on-that of growth and manufacture. In the chick, for instance, the frame is being built up rapidly, the feathers are coming out, and the flesh and muscles receive their daily increment. In the laying hen the egg is being formed. Now there are certain elements in the food that is taken that go to repair the waste and build up the body; they also enter largely into the manufactured product-the milk of the cow and the egg of the hen. These elements are called proteids. They are absolutely necessary to the life and health of the animal, and must be furnished in sufficient quantities or decay and death will ensue. 


\section{CARBOHYDRATES-THINGS THAT WARM UP.}

Besides building up food is required for another purposeto warm up. The temperature of the human body is 98 degrees; that of the hen's body, 103 degrees. To maintain the temperature of the body food must be burned in the stomach just as coal is burned in the furnace. You have noticed on a cold day in winter how difficult it is to keep up the temperature of a room up to 70 , and how much fuel is required to do it. And yet the temperature of the body must be kept 28 degrees above this, or the result will be a chill, from which we may never recover.

There are certain elements in the food that go directly to the production of heat, and these are called carbohydrates. They include sugar, starch and gums (sometimes called "nitrogen-free extract"), and the cellulose or fibre (the coarse or woody part of a plant) which, however, is indigestible. The cereals are especially rich in carbohydrates. We sometimes read that the farmers in Kansas and Nebraska, in years when the corn crop is excessive, use corn for fuel; and that is precisely what we do when we feed corn to our hens in the winter. The corn is the fuel which the hen burns to maintain the temperature of her body at 103 . Such being the case, the importance of a warm, snugly-built house to keep down fuel bills becomes at once apparent.

In a well conducted manufacturing establishment the fuel that is burned serves a double purpose; it not only generates the steam that warms the building, but it also generates the steam that drives the machinery. Perfectly analogous to this is the service rendered by the food elements that we denominate carbohydrates. They not only keep the body at a proper temperature, but they also furnish the energy by which the work is done.

\section{FATS-THINGS THAT ARE STORED UP.}

The careful and prudent head of a household is not content to "live from hand to mouth," as the saying is. He does not buy his coal from day to day, his flour a few pounds at a time, and his vegetables as he needs them to use. On the contrary he has a well-stocked cellar, in which are enough supplies to last for some time. The thrifty wage-earner does not spend quite all he earns, but saves a certain amount each week, which he deposits in a savings bank or invests in life insurance. Nature, our thrifty mother, is not content that her chil- 
dren shall live from day by day; so she lays by a reserve from which they can draw in time of need. This reserve is the fat which she wraps around the tissues and with which she en cases some of the organs.

There is one very curious thing that is true of the different food elements-they can take the place of each other, to some extent. This is not true of the proteids. Nothing can take their place. But it is true of the carbohydrates and the fats. At the New York State Experiment Station a cow was fed for 95 days upon food from which the fat had been extracted as thoroughly as possible. In spite of this absence of food fat the cow continued to secrete milk similar to that produced on a normal ration. Nearly sixty-three pounds of fat was yielded in the milk during the ninety-five days, and the cow gained forty-seven pounds during that time, being judged a much fatter cow at the end than at the beginning. This experiment would seem to be conclusive that the milk fat was produced quite largely, if not entirely, from the carbohydrates of the food. On the other hand, so well is it settled that fat may be converted into carbohydrates, that it is the common practice to multiply the fat by 2.25 to get its equivalent in carbohydrates in making up an equation.

Besides these three principle food elements which I have enumerated there are subordinate food elements as follows: Ash, representing the mineral ingredients after a food is burned. These ashes consist of lime, potash, soda, magnesia, iron, phosphoric acid and sulphuric acid. Water, present in all foods to some extent. Fibre or cellulose, the coarse or woody part of a plant (already mentioned under the head of carbohydrates, but more appropriately coming here).

\section{A BALANCED RATION, WIDE AND NARROW RA- TIONS.}

We are now in a position to frame our definitions. A balanced ration is a ration in which all the elements required to meet the needs of the animal for the time being are present in right proportion. It will be seen by this definition that a balanced ration is not a fixed and variable thing. A ration that is correctly balanced for chicks is not balanced for laying stock. and a ration that is balanced for laying stock is not balanced for birds that are being fattened for market. It has been found by experience that the ration of 1.2 (one part protein to two parts carbohydrates) is about right for chicks; the ration 1.4 
is about right for laying stock, and the ration 1.6 is about right for fattening. In making up the ration the ingredients are weighed, not measured, and the fat is multiplied by 2.25 (or $2 \frac{1}{4}$ ) to reduce it to carbohydrates.

A wide ration is one in which the protein is largely exceeded by the carbohydrates; a narrow ration is one in which the protein and carbohydrates are more nearly equal. As a matter of fact, anything exceeding 1.6 would be called a wide ration, and anything under it a narrow one.

\section{SOME THINGS TO BEAR IN MIND.}

The reader who has followed me carefully will see how absolutely impossible it is to feed a flock of hens by rule. common sense must come in. A ration that would be correctly balanced for one day would not be balanced for the next. For instance, on a very cold day in winter we burn twice as much coal to keep warm as on a mild day, and on the same day the flock would require a much wider ration (more carbohydrates or warming up food) than on a mild day or in midsummer.

Fortunately the hen has considerable power of adjustment, and so survives our well-meaning but bungling and imperfect efforts to feed her scientifically. If we do not feed enough, she draws upon her reserve; and if we feed too much she has the power of passing the excess through the body unassimilated. It is for this reason that I advocate feeding generously. Nature can take care of a surplus if it is not too great, but the only way in which she can meet a deficit is by drawing on her reserve.

The reader, too, will now see why it is that one poultryman feeds one way, and another another, and both have good results. The principal thing is to get your rations with succulent, nutritious food; and if you do this your hens are sure to respond with a goodly output of eggs.

\section{GREEN FOODS.}

What is the value of green food in the daily ration? Its great value is that it makes it more digestible; it lightens up the ration and makes it possible for the gastric juices to permeate every particle. Then, too, green food often contains certain mineral salts that the birds need, in a soluble and digestible form. Green food should form a portion of the daily bill of fare, either in the mash or separately. "In the winter and early spring months, mangel-wurzels, if properly kept, 
may be fed to good advantage. In feeding these beets to a flock of hens a very good practice is simply to plit the root lengthwise with a large knife. The fowls will then be able to pick out all the fresh, crisp food from the exposed cut surface. Cabbages can be grown cheaply in many localities and make excellent green food so long as they can be kept fresh and crisp. Kale and beet leaves are equally as good and are readily eaten. Sweet apples are also suitable, and, in fact, almost any crisp, fresh, green food can be fed with profit. The green food, in many instances, may be cut fine and fed with the soft food, but, as a rule, it is better to feed separately during the middle of the day, in such quantities that the fowls have about all they can eat at one time."

\section{CLOVER AS A FOOD.}

Clover is the green food, par excellence. Second-crop clover is best. It should be cut just as it is coming into bloom, or a little before, when there is a profusion of tender green leaves and the stalks have not become woody and dry. Great care should be taken in curing the crop. Clover for hens should be cut into short lengths, say one-fourth of an inch, and may be fed alone at noon. Or it may be mixed in the morning mash with boiling water. It is not necessary to steep it over night as some do. Clover is excellent, but somewhat expensive. 


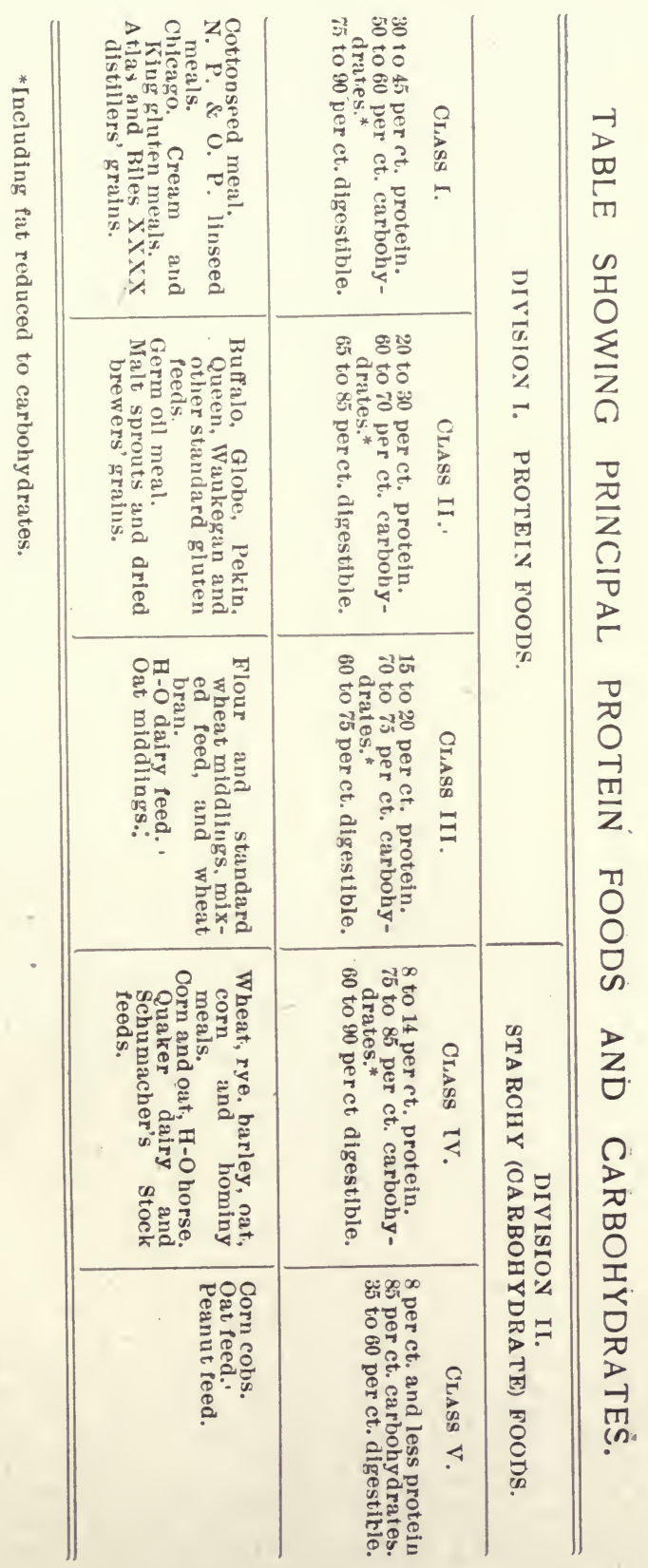


TABLE SHOWING COMPOSITION AND VALUATION OF PRINCIPAL FOODS.

\begin{tabular}{|c|c|c|c|c|c|c|c|}
\hline \multirow[b]{2}{*}{ FOOD STUFFs. } & \multicolumn{6}{|c|}{ Composition. } & \multirow{2}{*}{ 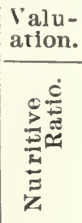 } \\
\hline & 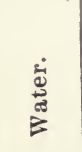 & $\frac{1}{4}$ & 竞 & $\sum_{\tilde{\Phi}}^{\stackrel{\dot{\Phi}}{\Xi}}$ & 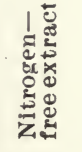 & 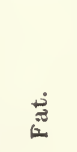 & \\
\hline PROTEIN FOODS. & & & & & & & . \\
\hline 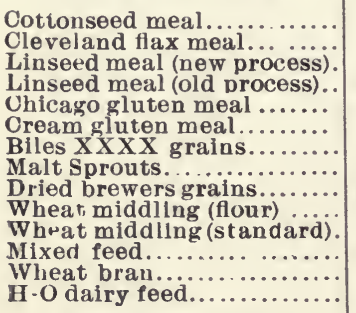 & $\begin{array}{r}7.0 \\
9.0 \\
9.0 \\
8.5 \\
9.5 \\
9.0 \\
8.0 \\
11.0 \\
8.0 \\
10.0 \\
10.0 \\
10.0 \\
10.0 \\
8.0\end{array}$ & $\begin{array}{l}6.5 \\
5.3 \\
5.5 \\
5.2 \\
1.0 \\
0.9 \\
1.8 \\
5.8 \\
3.8 \\
3.2 \\
4.3 \\
5.3 \\
6.2 \\
3.6\end{array}$ & $\begin{array}{l}4.5 .4 \\
38.3 \\
36.9 \\
34.6 \\
37.2 \\
34.3 \\
34.7 \\
27.1 \\
23.1 \\
19.4 \\
18.1 \\
17.1 \\
16.2 \\
18.3\end{array}$ & $\begin{array}{r}6.1 \\
8.8 \\
8.9 \\
8.6 \\
2.2 \\
2.2 \\
13.6 \\
11.9 \\
10.8 \\
3.2 \\
7.0 \\
8.4 \\
10.1 \\
12.7\end{array}$ & $\begin{array}{l}24.5 \\
36.2 \\
37.2 \\
36.8 \\
47.9 \\
51.6 \\
81.4 \\
42.6 \\
49.4 \\
59.4 \\
55.6 \\
54.6 \\
53.1 \\
53.4\end{array}$ & $\begin{array}{r}10.5 \\
24 \\
2.5 \\
6.3 \\
2.2 \\
2.0 \\
10.5 \\
1.6 \\
4.9 \\
4.8 \\
50 \\
4.6 \\
4.4 \\
4.0\end{array}$ & $\begin{array}{l}1: 1.0 \\
1: 1.1 \\
1: 1.1 \\
1: 1.5 \\
1: 1.4 \\
1: 1.6 \\
1: 1.6 \\
1: 1.7 \\
1: 2.1 \\
1: 3.1 \\
1: 3.7 \\
1: 39 \\
1: 3.4\end{array}$ \\
\hline \multicolumn{8}{|l|}{ ANIMAL FOODS. } \\
\hline 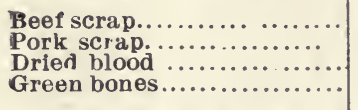 & $\begin{array}{l}1.3 \\
0.8 \\
6.7 \\
6.9\end{array}$ & $\begin{array}{r}8.0 \\
2.2 \\
6.6 \\
24.5\end{array}$ & $\begin{array}{l}58.0 \\
57.4 \\
65.1 \\
22.3\end{array}$ & $\mid \begin{array}{l}\cdots \cdots \cdots \\
\cdots \cdots \cdots \\
\cdots \cdots \cdots\end{array}$ & $\begin{array}{c}\ldots \ldots \ldots \\
\ldots .3 . \\
\ldots . . .\end{array}$ & $\begin{array}{l}32.9 \\
39.6 \\
16.3 \\
16.5\end{array}$ & $\begin{array}{l}11.3 \\
1: 1.6 \\
1: 0.6 \\
1: 1.6\end{array}$ \\
\hline \multicolumn{8}{|l|}{ STARCHY FOODS. } \\
\hline 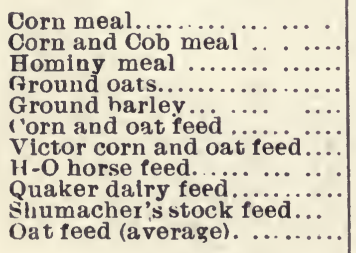 & $\begin{array}{r}14.0 \\
11.0 \\
9.0 \\
13.0 \\
13.0 \\
10.0 \\
10.0 \\
9.0 \\
8.0 \\
8.0 \\
7.0\end{array}$ & $\begin{array}{l}1.4 \\
144 \\
2.6 \\
3.3 \\
2.3 \\
3.0 \\
3.5 \\
3.2 \\
4.6 \\
4.1 \\
5.3\end{array}$ & $\begin{array}{r}9.5 \\
8.9 \\
11.2 \\
11.4 \\
11.3 \\
9.1 \\
8.7 \\
12.5 \\
13.2 \\
11.5 \\
7.8\end{array}$ & $\begin{array}{r}1.9 \\
6.7 \\
4.2 \\
8.7 \\
5.7 \\
10.0 \\
11.1 \\
9.8 \\
16.8 \\
11.4 \\
21.8\end{array}$ & $\begin{array}{l}69.9 \\
68.4 \\
61.2 \\
60.8 \\
65.8 \\
64.7 \\
63.1 \\
62.1 \\
54.3 \\
60.4 \\
55.3\end{array}$ & $\begin{array}{l}3.3 \\
3.6 \\
8.5 \\
3.8 \\
1.9 \\
3.2 \\
3.7 \\
3.4 \\
3.1 \\
46 \\
2.8\end{array}$ & $\begin{array}{l}1: 8.1 \\
1: 8.5 \\
1: 7.4 \\
1: 6 \\
1: 6.2 \\
1: 7 \\
1: 0.0 \\
1: 5.6 \\
1: 4.6 \\
1: 6.1 \\
1: 8\end{array}$ \\
\hline \multicolumn{8}{|l|}{ OEREA LS. } \\
\hline 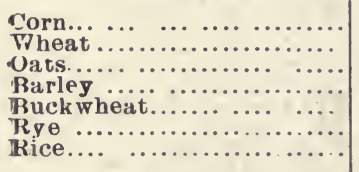 & $\begin{array}{l}10.9 \\
10.5 \\
11.0 \\
10.9 \\
12.6 \\
11.6 \\
12.4\end{array}$ & $\begin{array}{l}1.5 \\
1.8 \\
3.0 \\
2.4 \\
2.0 \\
1.9 \\
0.4\end{array}$ & $\begin{array}{l}10.4 \\
11.9 \\
11.8 \\
12.4 \\
10.0 \\
10.6 \\
13.0\end{array}$ & $\begin{array}{l}1.9 \\
1.8 \\
8.5 \\
2.7 \\
8.7 \\
1.7 \\
0.2\end{array}$ & $\begin{array}{l}70.3 \\
71.9 \\
59.7 \\
69.8 \\
64.5 \\
72.5 \\
23.9\end{array}$ & $\begin{array}{r}5.0 \\
2.1 \\
5.0 \\
1.8 \\
2.2 \\
1.7 \\
23.6\end{array}$ & $\begin{array}{l}1: 7.9 \\
1: 6.3 \\
1: 6.0 \\
1: 6.0 \\
1: 7 \\
1: 7.2 \\
1: 6\end{array}$ \\
\hline \multicolumn{8}{|l|}{ MILK. } \\
\hline 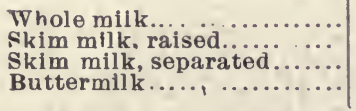 & $\begin{array}{l}87.2 \\
90.4 \\
90.6 \\
90.1\end{array}$ & $\begin{array}{l}\cdots \cdots \cdots \\
\cdots \cdots \cdots \\
\cdots \cdots \cdots\end{array}$ & $\begin{array}{l}3.5 \\
3.1 \\
2.9 \\
3.9\end{array}$ & $\begin{array}{l}\cdots \cdots \cdots \\
\cdots \cdots \cdots \\
\cdots \cdots \cdots \\
\cdots\end{array}$ & $\begin{array}{l}4.8 \\
4.7 \\
5.2 \\
4.0\end{array}$ & $\begin{array}{l}3.7 \\
0.8 \\
0.3 \\
1.0\end{array}$ & $\begin{array}{l}1: 3.8 \\
1: 2 \\
1: 2 \\
1: 1.6\end{array}$ \\
\hline
\end{tabular}




\section{CHAPTER VI.}

\section{Eggs in Fall and Winter.}

Unless a man breeds fancy fowls and has a good market in the spring for eggs for hatching, the gilt-edged profits come from eggs produced in late fall and early winter. There is no commodity that I know anything about where the price fluctuates so much in the course of a year as it does on eggs. In the local market eggs range in price from 12 to 15 cents in April and May to 30 to 40 cents around Thanksgiving. In spite of all that has been written and said about eggs in the late fall and early winter, there is always a shortage about this time, and there is likely to be for years to come.

The reason why it is so difficult to get eggs in late fall or early winter is that it is against Nature. The primary object of a bird in laying eggs is not to please the palate of the epicure or add to the profits of the owner, but to reproduce her

kind. Now it is a universal law that all creatures in a wild state bring forth their young at that season of the year when food is most abundant. The hen has been domesticated for more than thirty centuries, but back of this is a period of much greater extent when she was wild.

No artificial breeding or habitat can ever completely eradicate aboriginal instincts. The natural time for a hen to lay is in the spring and summer. It is evident, therefore, that in working for eggs in fall and early winter we are working against Nature, and can never hope for that complete success that we may expect when we are working with Nature and Nature is working with us.

\section{WINTER EGGS COME FROM PULLETS.}

Eggs in the fall and winter come principally from pullets. At Thanksgiving time, when eggs are at their maximum, the hens have not fully recovered from their moult. They may lay a few eggs, but nothing great. Those who get winter eggs in large quantities are those who follow the advice of this book and plan to have at least two-thirds of their laying stock pullets. But not every pullet is a layer. It is only those that are well grown and have been handled right that are now giving a good account of themselves. The first great rule 
for winter eggs is as follows: Get out your chicks early and keep them coming from the day they break the shell down to the day they go into the laying pens in the fall.

\section{AMERICAN BREEDS BEST.}

The breed has something to do with it. As a rule the American breeds are the best winter layers. I know that this statement will be challenged, and that instances will be given where the Mediterraneans or Asiatics have equaled or surpassed the Americans in egg production; but the statement will stand. The Mediterraneans are thin-feathered and are very susceptible to climatic conditions. A sudden cold snap will often cause the egg product to drop to zero. The Asiatics, on the other hand, are thick-feathered, but slow in maturing-they, do not get ready to lay until well on toward spring. The man who wants winter eggs will make no mistake if he fills his pens with well matured pullets of the American class.

\section{A WARM HOUSE ESSENTIAL.}

In olden times hens were not expected to lay in winter. No wonder they did not! They were not hatched out until June, and were expected to pick up their living in the fields. After it became too cold for them to roost in trees they were allowed to stay in the barn nights, roosting on the big beams, or were thrust down into the noisome barn cellar. A few handfuls of corn were thrown down to them from time to time, and if they wanted to quench their thirst they could eat snow or break the ice in the horse trough. It is a marvel they ever lived through the winter, to say nothing of laying eggs. Even to-day, when poultry keeping is so much better understood, the importance of a warm house is not half enough appreciated.

The West Virginia Experiment Station a few years ago scientifically demonstrated the importance of a warm house in the production of winter eggs. "Two houses situated side by side and similar in all respects were selected for the experiment. The houses had been constructed with matched siding and shingle roofs. Before the experiment began, one house was sheathed on the inside with boards and then thoroughly papered so as to cover all the cracks. The experiment began November 24th, and continued for five periods of 30 days each. The two flocks were fed the same kind and amount of food. The total number of eggs produced per 
100 hens in the warm house was 5,239, while in the cold house 100 hens laid but 4,136 eggs in the same time, a balance in favor of the warm house flock of 1,103 eggs worth in the local market 24 cents per dozen, or $\$ 22.06$. It is thus seen that the additional expense for increasing the warmth of the house was a very profitable investment."

\section{FEEDING FOR WINTER EGGS.}

Readers of the preceding chapter of this book will need no special instruction in the production of winter eggs, but it will do no harm to repeat the substance of what I have said. To get eggs in winter, or, indeed, at any season of the year, it is necessary to feed generously. One cannot get something for nothing, and if one is to get plenty of eggs from his hens he must supply them with the raw materials for egg making. "Overcrowding and underfeeding are two serious hindrances to a good egg yield; but underfeeding is by far the more serious hindrance to a profitable winter's work with the layers." So the second great rule for winter eggs is: Give plenty of good wholesome food and give variety, if you want winter layers.

\section{EGG FOODS AND TONICS.}

The question comes up in this connection as to the expediency of using egg foods and tonics where winter eggs are wanted. On the one hand there are some who recommend their use; on the other there are those who unqualifiedly condemn. Theoretically, I suppose, it is better not to use them; but, actually, they may be used occasionally to good advantage. I suppose it would be better for a man never to overwork, but to consume each day only so much energy as he made. But, as a matter of fact, there come occasions into the life of every busy man when he is compelled-to work sixteen or eighteen hours at a stretch, day after day, and draw upon his reserve. Nature allows him to do this, but only on condition that he make up the deficit as soon as he can. Nature is like a bank that allows a good customer occasionally to overdraw. It will do no harm to stimulate a healthy, well-grown bird a little when eggs are high; but to use stimulants and conditions powders habitually is to defeat the very purpose for which they are made-they either kill the hen or she becomes immune and no longer responds. 


\section{\$100.00 IN GOLD: HOW MR. S. D. FOX WON IT.}

Some years ago the manufacturers of a well-known condition powder advertised a "Gold Coin Premium Contest" for the best egg record during the winter months, in which $\$ 200.00$ in gold was to be given to sixteen contestants. There was one first prize of $\$ 100.00$, five prizes of $\$ 10.00$ each, and ten prizes of $\$ 5.00$ each. The contest was open to the world. The conditions were that each contestant must keep not less than twelve hens, must buy at least one dollar's worth of condition powder, and must make a full four months' trial. The time for the close of the contest was set at April 1st. The first prize was won by Mr. S. D. Fox of Wolfeboro, N. H. Unfortunately Mr. Fox kept no records other than those he sent in, and in a general clearing up of the central office a short time since all records relating to the contest were destroyed. Consequently I am unable to give the figures, but it may be enough to state that out of the hundreds of contestants Mr. Fox won the first prize. I will give his methods, as nearly as possible in his own words:

"That fall," said Mr. Fox, "I had a master fine lot of hens -White Wyandottes, with just a dash of Leghorn blood in 'em to make 'em lay. They were hatched early, and I began to get eggs from them in October. When I saw the contest advertised I thought I would enter. I didn't expect to get the first prize, but thought possibly I might get one of the others. So I bought a dollar's worth of condition powder of C. W. Hicks, who then kept the Wolfeboro Drug Store, and started in. I remembered reading in an old book the following sentence: 'There is nothing that will make hens lay equal to cayenne pepper and milk.' I had a cow that came in in the fall, which was giving about sixteen quarts of milk a day. I made up a pen of the likeliest looking pullets, and started in. I fed them in the morning a mash made of equal parts of corn meal, ground oats and bran. I didn't know anything about meat meal or ground bone in those days, and so I put in instead a handful of linseed meal and what scraps we had left from the table. I mixed this mash up with warm skim milk. Two or three times a week I shook into the milk a teaspoonful of cayenne pepper. I gave the hens all the mash they would eat up clean. At noon I fed oats and at night corn. I gave the hens all the milk they would take. I gave it to 'em sweet; I gave it to 'em sour; I gave it to 'em in the form of curd. There were days when they had no water-nothing 
but milk. Lay? You never saw anything like it! I wish I could remember how many they laid. Anyway they laid enough to bring me the first prize of $\$ 100.00$. Give me cayenne pepper and skim milk, and I'1l risk but what I can make hens lay every time."

\section{R. FOX'S HEN PERSUADER.}

"I can give you a receipt for an egg food and tonic that will do the business," said Mr. Fox. "I sent off once for an egg food that was highly advertised, and the first thing I knew it had killed five hens. No, I guess I won't give you the name. Maybe I was a little anxious to haye 'em lay, and fed too much of it. But this one I can vouch for. It is the greatest hen persuader I know anything about. I fed it one winter to seventy-two hens, and one day got sixty-eight eggs. Five days in succession from the same flock I got sixty-four eggs. Take ten pounds of bone meal, ten pounds beef scraps, five pounds fenu-greek, two pounds sulphur, two pounds charcoal, one-half pound cayenne pepper, one-half pound salt. Mix and keep. Put a half pint in the mash every morning for twenty hens. When you feed this egg food, feed no meat meal or meat scraps, and do not salt the mash. You will get the mixture right if you remember that the combined weight of the ingredients is thirty pounds. It costs about a dollar and a half to make it."

TO START PULLETS TO LAYING IN THE FALL.

When pullets are old enough to lay and do not lay they need some slight shock or change to start them in. The majority of those who rear chickens give them free range, or as near free range as possible, during the summer months. This is correct. But after they get their growth their energies need to be directed to egg production and not run off in useless exercise. Accordingly as early as October 1st-if not before -the pullets should be taken from the range and put into the laying houses. Here their range should be restricted. More meat meal or ground bone may be advantageously introduced into their ration, and a stimulant may be given in the shape of cayenne pepper or condition powder. This treatment soon induces egg production, if they are of the "bred-to-lay" kind. 


\section{CHAPTER VII.}

\section{The Sex Element in Egg Production.}

Why do hens lay at all? This is the most momentous question that confronts the poultryman. If he can answer the question correctly he is in a position to proceed intelligently and systematically with egg production. If he cannot answer it, or has never even thought of it, he is in no condition to get a large and uniform egg yield. He may make a hit occasionally, but there will be years when eggs will be few and far between.

It is evident to the most casual observer that hens do not lay for their own amusement-for the fun it gives them. Anyone who has ever watched a hen straining to discharge the egg, or who has taken an egg out of a nest blood-stained from some internal hemorrhage, must realize that the passage of an egg by a hen is not for her altogether an agreeable operation. Doubtless there is a sense of relief when the egg is expelled-but so there is when a man has had an ulcerated tooth extracted. Nor do hens lay to add to the profits of their owner. It is a common complaint, and one in which there is a good deal of truth, that hens lay only when eggs are cheap and shut down when they are dear! No, hens do not lay for fun or to add to the bank account of their owner; they lay for an altogether different purpose.

Implanted in the core and center of every living thing is the desire to reproduce its kind. It seems to be the design of Nature that the species shall be perpetuated at any cost. "Multiply and replenish the earth" is a command addressed to plants, animals and birds as well as to man. So imperious is this instinct of reproduction, so irresistible, that some of the lower orders propagate at the cost of-their own lives.

The hen lays to gratify the imperious instinct of reproduction. In her wild state the hen lays from six to ten eggs a year. She lays them in some secluded nook in the jungle, that she may rear her little brood. If it were not for this instinct of reproduction the hen would never lay. We have taken this instinct of reproduction, stimulated it so that the domestic fowl now lays from ten to twentyfold as many eggs as her aboriginal ancestress; but have largely forgotten, if 
we ever knew, that it is the presence of this instinct that makes egg production possible.

\section{CONDITIONS OF REPRODUCTION.}

What are the conditions of reproduction? They are five, and they are as follows:

1. Maturity. The animal, bird or plant must be in the intermediate state' between growth and decay. The desire for reproduction is greater at the beginning of this intermediate state, and steadily declines toward its end. This is why a fowl will lay more eggs the first year after coming to maturity than in any subsequent year of her life.

2. Vitality. Reproduction draws upon the vital forces as does no other act. This is why the bird feels a desire to incubate after her litter is completed-she needs rest. The broody hen should be treated with great consideration, and not ruthlessly abused, as is too often the case. The immediate effect of disease or injury is to weaken the desire for reproduction. A sick hen is not a laying hen.

3. Nutrition. The animal, bird or plant must be well fed. Darwin makes nutrition the principal factor in reproduction. He says: "With hardly an exception our domesticated animals, which have long been habituated to a regular and copious supply of food, without the labor of searching for it, are more fertile than the corresponding wild animals. The amount of food affects the fertility of even the same individual; thus sheep, which on mountains never produce more than one lamb to a birth, when brought down to lowland pastures, frequently bear twins. As Mr. Dixon has remarked, "High feeding, care and moderate warmth induce a habit of profligacy which becomes in some measure hereditary.", (Animals and Plants Under Domestication, vol. ii, chap. xvi.)

4. Sanitation. Sanitation profoundly affects vitality, and without sanitation the other conditions cannot produce their full effect. The hen house should be kept perfectly clean, the birds free from parasites; they should not be crowded, and should be supplied with everything necessary to comfort and health.

5. Sex. In the very lowest forms of life reproduction is a sexual-that is, the new life is produced not by the coming together of male and female, but by fission or cleavage from the parent organism. But all higher animals and plants are represented by distinct male and female forms, and the more 
completely each form is sexed the greater its power of reproducing its kind.

\section{THE SEX ELEMENT IN REPRODUCTION.}

The importance of the sex element in reproduction has never been fully understood. Splendid work is being done at experiment stations and by independent investigators in the study of the domestic fowl. The trap nest has enabled us to select the hens that lay the most eggs, and to breed from them. Nutrition has been studied, until we can feed with almost mathematical certainty but the study of sex has been neglected. It may be that the study of sex requires a knowledge of physiology and biology that is lacking in the case of most poultrymen; but it is here that the richest field lies, and when a man has mastered the subject of sex he is in a condition to obtain a large and uniform egg yield with the minimum amount of cost and labor.

\section{BREED FROM THE BEST SEXED BIRDS.}

The greatest secret of large and uniform egg production I believe to be this: Breed from the best sexed birds! Poultry writers are reviving the old question as to whether or not there is an egg type. I am inclined to think there is. But the egg type that I care most about is one based on sex. The male that is the most distinctly male and the female that is the most distinctly female are the birds for me.

By keeping this principle in mind $I$ have succeeded in building up a strain of birds that are splendid layers. I do not use the trap nest, and s.o am not able to give individual records. I did have a bird once that laid an egg that allowed me to keep tab on her as accurately as if I had used the trap nest. From some peculiarity of the ovaries the egg had a ring around it about one-third of the distance from the smaller to the larger end; it was ivory white in color and of medium size. It was such an egg as I could not very well mistake. In fourteen months and ten days more than 300 of these eggs appeared. The hen then became broody, and I foolishly allowed her to sit. After she had completed the process of incubation and weaned her chicks, so much time had been lost that I did not attempt to keep tab upon her again. I have given up pushing my hens for big egg production, but take what comes along. When conditions are right I get from 150 to 200 eggs a year apiece from my best layers and with that I am satisfied. 
HOW I APPLY THE PRINCIPLE OF SEX SELECTION.

And now I will tell the readers of this chapter how I apply the principle of sex selection. I keep a close watch over my chicks from the day they break the shell, and as soon as one shows its sex that chick is marked so that I can tell it afterward. When the chicks are three months old the first separation is made; males and females are separated, and the chicks that showed their sex first are taken from the rest. This gives me four flocks. From the chicks in which the sex element first manifested itself I expect to get my best layers. When it is time to put the birds in the winter quarters another separation is made-the birds that show they are nearest ready to lay are put in pens by themselves. (I do not care for precocious pullets, but when pullets have had time to mature the ones that are nearest ready to lay are in my judgment the best pullets.) The final selection for the breeding pens is made when birds are about 18 months oldthe ones which moult the earliest and most rapidly being selected for breeders. Thus by a consistent application of the principle of sex selection I get my strain.

With the males the same principle is applied. The birds that show their sex the earliest and the most strongly are reserved, and the others are killed and sent to the market. Any judge will tell you that "good wattles are a sign of a good bird." But besides having good wattles a breeding cockerel should have other qualities; he should be vigorous, alert, courageous, well grown, with decided protuberances on his shanks where later the spurs are to be. In other words he should be strongly sexed.

I believe that anyone who will consistently and intelligently follow out the suggestions given in this chapter will see his egg yield steadily improve, and that in three breeding seasons, with comparatively little trouble, he will get the 200-egg hen.

THE LAW OF SEX: MALES OR FEMALES AT WILL.

One of the most interesting problems that confronts the biologist is that of sex. What are the conditions that produce a male organism and what the conditions that produce a female? It is obvious that in a world where everything is by law sex is not by chance, but what the law is we do not fully know. Still many facts have been gathered, and we are nearing the goal. The poultry business offers a peculiarly favorable field for investigation. When you reflect that per- 
fect organisms may be produced in any.number in the short space of twenty-one days, the parent fowls may be kept under such conditions as the investigator may wish and that these conditions may be varied at will, that the embryo may be followed through all the stages of its development, you realize at once what a field the poultry business presents for a study of the problem of sex, and the business takes on a new dignity and interest.

Some very important facts bearing on sex have been gathered. The point on which investigators are more fully agreed is that nutrition has a profound influence upon sex. Beginning with insects it has been found that if caterpillars are starved before entering the chrysalis state the resultant butterflies or moths are males, while others of the same brood highly nourished are females. With bees, too, the relation between nutrition and sex seems equally well established. Experiments with tadpoles, which were supplied with a diet steadily increasing in sumptuousness, showed a steady and corresponding increase in the number of females produced. The proportion of females to males, which was originally fifty-seven to forty-three, rose steadily as the diet became more and more highly nutritious, until out of 100 tadpoles ninety-two were females and eight males. Coming up in the scale of life it has been found that among mammals the same principle holds, although of course other influences come in more than among the lower orders.

Another feature that is believed to have an influence upon sex is the time of impregnation. The fresher the ovum when fertilized the greater the likelihood that the offspring will be a female. If this conclusion is correct eggs laid at the beginning of a litter should hatch a larger proportion of pullets than eggs laid later.

The relative age of the parents is believed to affect the sex. Where the male parent is the older the offspring are preponderatingly male, and where the ages are even, or where the mother is the superior in age, the preponderance is the other way. I find that this is a theory quite generally held. I sometimes receive letters from would-be purchasers asking for eggs from hens mated with cockerels. It is a theory very easy to test, and the reader should give it a trial in his yards.

Temperature is also a feature to be reckoned with. I have noticed in my own yards that in the cold months the proportion of pullets hatched is smaller than it is later in the 
season. Take the plant lice which multiply so rapidly upon the rose bushes, fruit trees, and the like, and which are known to science as aphides. "During the warmth of summer, when food is abundant, these insects produce parthenogenetically nothing but females, while in the famines of later autumn they give birth to males. In striking confirmation of this fact it has been proved that in a conservatory where aphides enjoy perpetual summer, the parthenogentic succession of females continued to go on for four years, and stopped only when the temperature was lowered and food diminished."

In my own experiments and observations I have found several things influencing sex that I have not found mentioned by the authorities. One of these is affinity. I have found that where there is perfect affinity, and the birds are happy and contented, the conditions are right for the production of females; but where the birds are not well mated and frequent quarrels ensue the offspring are likely to be largely males. Another thing is freedom from disturbance and fear. Where hens are kept stirred up by the presence of strangers or shifted frequently from place to place their eggs are quite sure to hatch an excess of males. The quieter you can keep your hens the more pullets you will get.

The greater the number of females to a male the more pullets. I know a man who mated two roosters to 118 hens, and out of 135 chickens hatched $10^{\circ} 7$ were females.

Now let me sum up all that has been said in language of another: "Such conditions as deficient or abnormal food, low temperature, deficient light, moisture and the like, are obviously such as would tend to induce a preponderance of waste over repair-a katabolic habit of body-and these conditions tend to result in the production of males. Similarly, the approved set of factors, such as abundant and rich nutrition, abundant light and moisture, favor constructive processes, that is, make for an anabolic habit, and these conditions result in the production of females. With some element of uncertainty we may also include the influence of the age and of physiological prime of either sex, and of the period of fertilization. But the general conclusion is tolerably secure, that in the determination of sex influences inducing katabolism (or waste) tend to result in the production of males, as those favoring anabolism (or repair) similarly increase the probability of females."

This is the law of sex, so far as it can be stated at present. 


\section{CHAPTER VIII.}

\section{The Trap Nest and Its Users.}

Within the past few years the outfit of the poultryman has been enlarged by the addition of the trap nest. As to the practical value of these nests there is a wide difference of opinion; on the one hand they are enthusiastically advocated; on the other they are scornfully condemned. The trap nest needs a judicial appraisal. It has been unfortunate in both its enemies and its friends. Many of those who have ridiculed it have never tried it, and those who have advocated it have too often been those who are interested in it in a financial way.

The principle on which the invention rests is that of the influence of heredity. It is a fact well known to all breeders of animals that desirable traits may be transmitted, and by careful mating a strain may be permanently established. It is a matter of common knowledge that in the poultry world some of the most popular breeds of to-day have been made within a comparatively recent time by the combination of in dividuals of different varieties. It would seem almost axiomatic, therefore, that if one wishes to establish a heavy-laying strain he must breed only from heavy layers. In the preceding chapter I have told how these layers may be picked out. But there is always the possibility that the poultryman may be mistaken. The trap nest box may be used in the breeding pen for a time at least to supplement the poultryman's personal observation. It is not necessary to use it all the year round, or to use it in all the pens; but it may be used at times in certain pens to good advantage to ascertain if all the hens are laying, and to weed out hens that are not doing so well as their owners think they ought, and hens that lay small, misshapen or poorly-colored eggs.

The fancier also may make good use of the trap nest in the breeding season, to enable him to select the eggs of individual layers. He may have in a pen a hen of unusual beauty or excellence, the offspring of which he desires to keep for his own use. The trap nest will enable him to pick out the eggs this hen lays, and then by markings on the feet of chicks hatched from these eggs it is easy to tell them from the rest. 
THE GOWELL TRAP NEST.

There are many trap nests on the market. The right to use these nests, with plans for their construction, costs from one to three dollars. Through the courtesy of Mr. G. M. Gowell, agriculturist of the Maine Experiment Station, I am able to present my readers with the plan for a nest box free of charge. The nest box here described was made by Mr. Gowell after a careful study of the various nest boxes on the

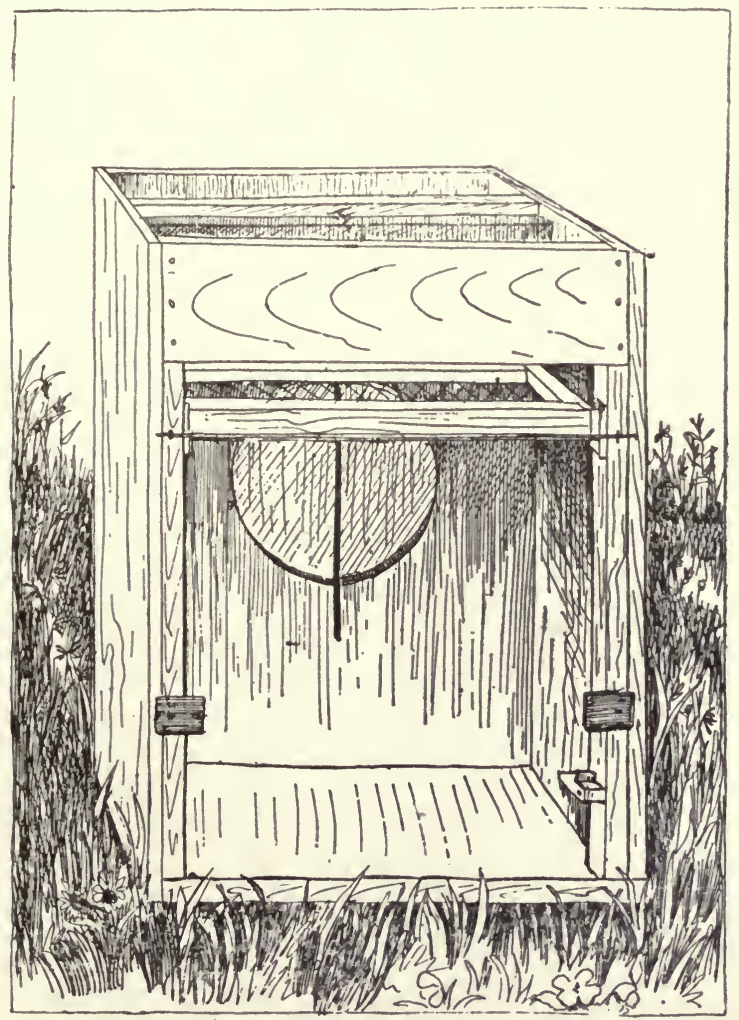

Single Nest Box.

market, and is intended to combine their excellences and avoid their defects. This is the box that is illustrated here, and the description of it is in Mr. Gowell's own words:

"The nest box is very simple, inexpensive, easy to attend, and certain in its action. It is a box-like structure, without end or cover, and is twenty-eight inches long, thirteen inches wide and thirteen inches deep-inside measurements. A di- 
vision board with a circular opening seven and one-half inches in diameter is placed across the box twelve inches from the back end and fifteen inches from the front end. The back section is the nest proper. Instead of a closed door at the 61 trance, a light frame of inch by inch and a half stuff is covered with wire netting of one-inch mesh. The door is ten anit one-half inches wide and ten inches high and does not fill the entire entrance, a space of two and a half inches being left at the bottom and one and a half inches at the top, with a good margin at each side to avoid friction. If it filled the entire space it would be clumsy in its action. It is hinged at the top and opens up into the box. The hinges are placed on the front of the door rather than at the center or back, the better to secure complete closing action.

"The trip consists of one piece of stiff wire about three-sixteenths of an inch in diameter and eighteen and one-half inches long, bent as shown in drawing. A piece of board six inches.

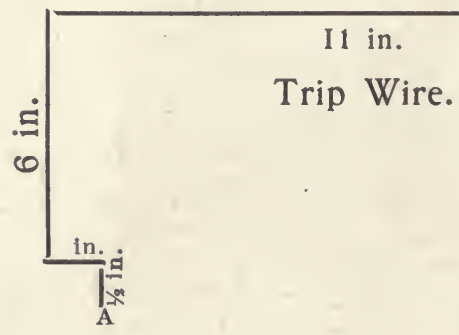

wide and just long enough to reach across the box inside is nailed flatwise in front of the partition and one inch below the top of the box, a space of one-fourth of an inch being left between the edge of the board and the partition. The purpose of this board is only to support the trip wire in place. The sixinch section of the trip wire is placed across the board and the long part of the wire slipped through the quarter-inch slot. and passed down close to and in front of the center of the seven and a half inch circular opening. Small wire staples are driven nearly down over the six-inch section of the trip wire into the board so as to hold it in place and yet let it roll sidewise easily.

"When the door is set, the half-inch section of the wire marked A comes under a hardwood peg or tack with a large round head, which is driven into the lower edge of the door frame. The hen passes in through the circular opening and in doing so presses the wire to one side, and the trip slips from its 
connection with the door. The door promptly swings down and fastens itself in place by its lower edge, striking the light end of a wooden latch or lever, pressing it down and slipping over it; the lever immediately coming back into place and locking the door. The latch is five inches long, one inch wide and a half inch thick, and is fastened losely one inch from its center to the side of the box, so that the outer end is just inside the door when it is closed. The latch acts quickly enough to catch the door before it rebounds. It was feared that the noise arising from the closing of the door might startle the hens, so instead of wooden stops pieces of old rubber belting were nailed at the outside entrances for the door to strike against.

"The double box with nest in the rear end is necessary, as when a bird has laid and desires to leave the nest, she steps to the front and remains there until released. With one section only, she would be likely to crush the egg by standing upon it."

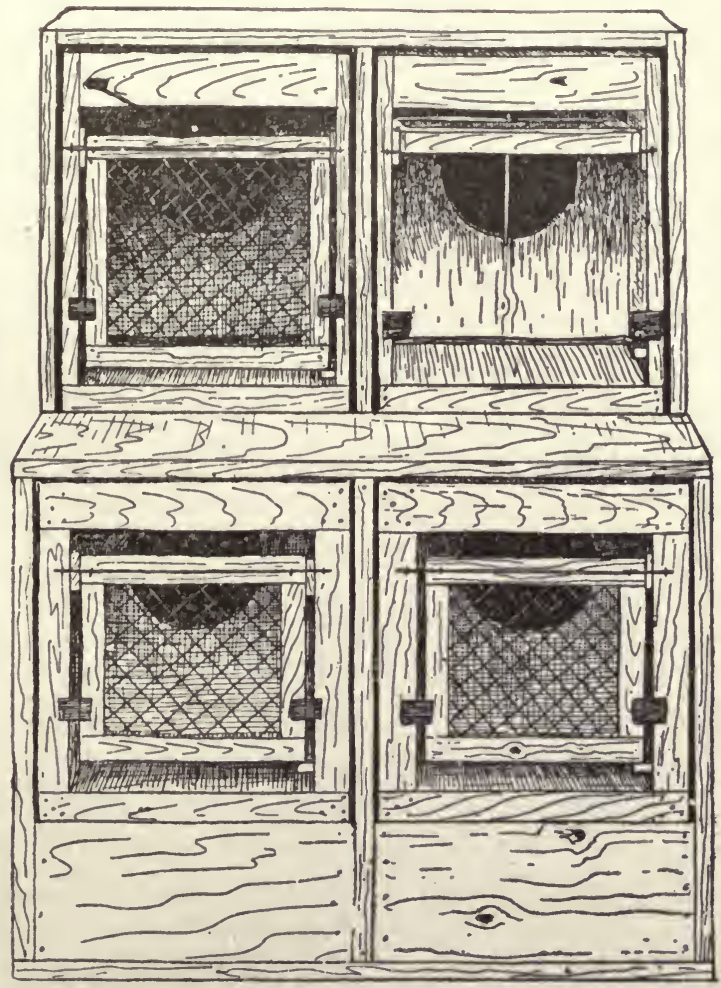




\section{CHAPTER IX.}

\section{Breeding for Two Hundred Eggs a Year.}

Most of our domestic animals and birds are descendants of some wild prototype. In the zoological gardens of Hamburg and New York are living specimens of the primitive wild horse of Central Asia-funny, big-headed little brutes that are representatives of some type of horse that must be hundreds of thousands of years old. Dogs are descendants of wolves and jackals and perhaps of one or two species of wild dogs that have become extinct. Pigeons trace their ancestry back to the rock pigeon, which has a vast range from Northern and Eastern Europe to the shores of the Mediterranean, to Madeira and the Canary Islands, to Abysinia, India and Japan.

For the prototype of our domestic fowl we must go to Asia, and especially to Northern India, where the Himalayas lift their snowy crests far up into the sky. Here we shall find a bird running wild through the dense forests and jungles, which is believed to be identical with the parent type from which all domestic fowls have come. The bird closely resembles the black-breasted Indian Game, with which we are all familiar, albeit somewhat smaller in size and carrying the tail more horizontally. From this bird have come all the varieties of our domestic fowls-the Stately Spanish, the Crested Polish, the lordly Brahma, the elegant Leghorn, the practical Plymouth Rock, the snowy Wyandotte and the diminutive Bantam. Natural and artificial selection, continued for many years, has created all these differences.

Even more remarkable than the difference in plumage and form that have been brought about by breeding is the difference in egg production. Gallus Bankiva, as this wild jungle fowl is called, lays from six to ten eggs a year, while some of our domestic fowls have been known to lay over 300. This vast increase in egg production has been brought about by improved nutrition and by breeding from prolific layers. In other chapters I have emphasized sufficiently the importance of care and feeding in egg production; in this I wish to call attention to the subject of breeding. 
THE THREE LAWS OR PRINCIPLES UNDERLYING REPRODUCTION.

Breeders now recognize three laws or principles underlying the whole subject of reproduction. 1. Inheritance. By inheritance is meant the tendency of parents to repeat themselves in their offspring, and of offspring to resemble their parents. It is because of this law of inheritance that anything like scientific breeding is possible. If parents did not have a proclivity to repeat themselves in their offspring and if offspring did not have a proclivity to resemble their parents, the breeder might well abandon his task as hopeless. 2. Variation. By variation is meant the tendency of offspring to differ from the parents. The infant is never an exact copy of the father or mother; it possesses an independent individuality of its own. thus the product of $A$ and $B$ is never $A$ or $B$, even $A B$ or $\mathrm{BA}$; it is $\mathrm{AB}$ plus $\mathrm{X}$; in other words there enters in an unknown element to influence the result. It is this law of variation that makes it possible to improve the species; the parents may be so mated that the offspring will be better and stronger than either one of them. 3. Reversion. There is a propensity to go backward as well as forward-to return to some primitive type. Where mating is indiscriminate the tendency to reversion is very strong.

\section{BREED FROM YOUR BEST BIRDS.}

We have now reached the point where it is possible to formulate some rules for breeding. The first is this: Breed from your best birds. By best birds I mean birds that will best enable you to reach your ideal. If your ideal is beauty breed from birds that will give you beauty; if your ideal is utility breed from birds that will give you utility. We now see why it is so difficult to have a show bird and an egg bird in the same specimen. The breeder must sacrifice somewhere-either on the score card or the egg record. It is possible to have a good looker and a good layer in the same bird; but I do not believe that it is possible to have a bird that will win in Boston, New York or Chicago, and at the same time lay 200 eggs a year. The reader must make his choice. I have made mine. Utility first, beauty afterward. I like to see a beautiful bird as well-as anyone, but I can't afford to breed for plumage and points. My White Wyandottes sometimes show some brass; they stand higher than I like; but they will lay-summer and win- 
ter, hot or cold, wet or dry-lay so that I sometimes fear they will lay themselves to death. They are a money-making proposition for me and for my customers, even if they cannot win at the big shows.

\section{BREED FROM MATURE BIRDS.}

The only bird fit to breed from is one that is in good health and thoroughly mature. Probably the best mating is a vigorous, well-grown cockerel with year-old hens; next to that a cock with mature pullets. A pullet should have laid out at least one litter before she is put into a breeding pen. Even then it is better not to use her, if you can help it. There is no surer way of running out a flock than to breed from immature birds.

\section{THE MALE.}

You often hear it said that "the rooster is half the pen." It is meant by this that one-half the blood of the offspring will come from the male side. Such being the case it is highly important that the cock or cockerel should be a good bird. A few paragraphs back I spoke of the fact that the hen in her wild state laid from six to ten eggs a year. The average farmer's hen lays from 75 to 100 eggs in the same time. What has made the increase? It has come, as I have said, from improved nutrition and from selection. But the selection has all been on the male side! It is the practice on the farm, and I doubt not has been for generations, to keep the best male to breed from, but to breed indiscriminately from the females. The fact that under such haphazard methods of keeping fowls as have prevailed in the past, egg production has increased tenfold, is a remarkable tribute to the value of the male as an agent in building up the egg yield.

\section{CONCERNING CROSSES.}

You will find a strong tendency on the part of the average poultry keeper to mix up his birds. If he gets a flock of fowls that begin to look alike, ten to one he will buy a rooster of a neighbor for a dollar of some entirely different breed, and the result will be that the next fall he will have a whole poultry show on his hands. There is a popular belief that crosses lay better than thoroughbreds, and the method of procedure is to mix up the birds as much as possible.

This whole subject of crossing needs to be better understood. Some good must come from crossing, or it would not 
be so universally practiced. Where does it come from? It comes from the invigoration that always follows the introduction of new blood. The cross-breed pullet lays better than its mother because it is larger and stronger-it can eat and assimilate more and stand the strain of egg production better. The average farmer's flock is constantly running out. He does not breed from his best. The introduction of new blood counteracts this tendency. Consequently the farmer is converted to a belief in the superiority of the cross.

But when you go beyond the first cross-when you crisscross, as they say-you strike another tendency-the tendency to reversion. The mixing of bloods results in bringing out ancestral characters. The criss-cross is not far removed from the red jungle fowl, and there inevitable comes a drop in egg production:

All the valuable results that come from crossing can be secured by the occasional infusion of new blood from a male of the same breed as your own, and the breed may be kept more pure. It is not necessary to introduce new blood oftener than once in two years. Suppose you send away for a cockerel this fall. The first mating will be with birds with which he is entirely unrelated. Next fall mate him to the best pullets of his own get, and take the best cockerel to mate with the hens in the other breeding pen. If you find a strain of birds that you like follow along with the breeder, getting a male from his yards every two years.

Breeders for fancy points breed in and in, and have a chart of matings that is as intricate as a bicycle road map. It is impossible to produce show birds that will win in the hottest competition without in and in breeding. But the reader of this book has no necessity to resort to any such procedure-that is if he is after eggs first and not feathers and frills.

FERTILE EGGS AND HOW TO GE'T THEM.

To get fertile eggs three things are necessary-maturity, vitality, comfort. The conditions in the breeding pen must be such as to promote maximum vitality. Where the male is immature, where the house is so cold that the food eaten goes to maintain the caloric, where the fowls are alive with vermin or rotten with disease, the fertility will be low. Inbreeding also tends to fertility. So does lack of exercise and overfat condition of fowls in the breeding pen.

Doubtless diet has an important effect upon fertility. Unless every element needed for the embryo is present, the egg 
will be infertile or the chick will die in the shell. There are some kinds of food that stimulate the genital organs and promote sexual activity. Raw onions chopped fine and fed in the mash twice a week are excellent during the breeding season. Clover is also a valuable food for fertility.

Where fertile eggs are wanted the hen must not be pushed too hard for egg production. My own method is to push my pullets the first year. I reserve the best layers to breed from, and do not push them the second year; but let them take things easy. They have made their record and deserve a rest. When the breeding season comes they are in prime condition, and lay large, highly colored eggs which hatch hardy chicks.

It pays to alternate males where high fertility is desired, allowing three males for two pens, keeping two in active service and the third shut up to rest. Cocks have their favorites, and where one male runs with a flock some hens are neglected; but where males are alternated all are likely to be served.

Many eggs fail to hatch because they are not properly cared for. It takes but little to kill the germ. One reason farmers get such poor results in winter is that they are not careful to gather their eggs several times a day. The opinion is common among them that an egg must be frozen hard enough to crack the shell before it is unfit to put under a hen. Eggs should be gathered when warm and kept in a temperature of from 40 to 60 degrees. In shipping eggs to customers they should be moved in the middle of the day and protected from extremes of temperature as much as possible.

\section{WHY EGGS ARE NOT FERTILE IN WIN'TER.}

Also every winter some person of my acquaintance buys an incubator and starts in to raise broilers for the city market. The result is inevitably disappointment. The percentage of fertility is so low and the mortality among the chicks so great, that the books show a loss instead of a profit at the end of the season. The reason why the fertility is so low in winter is purely physiological. "The testicles of birds vary greatly in size according to the season of the year in which they are observed. In winter they are very small, with a comparatively insignificant blood supply; but in spring, as the breeding season comes on, they enlarge to five or ten times the weight during winter, the vessels are distended with blood and the height of functional activity is reached." To get fertile eggs in winter, therefore, the house must be warm, or eggs must be imported from the South. 


\section{CHAPTER X.}

\section{Incubation-Artificial and Natural.}

As the poultry business is now conducted it is the practice for each poultryman to get out enough chicks in the spring to supply him with layers in the fall. There is no reason, however, why the great law of specialization should not obtain in the poultry business as in nearly every other, and why in the future we should not have entire plants devoted to the rearing of young stock and other plants devoted wholly to the production of eggs. At present, however, it is necessary for the poultryman to know how to raise his own chicks, if he wishes to succeed.

It is a good rule on a poultry farm to have at least twothirds of the laying stock pullets. Suppose then a man intends to keep 300 head of laying stock always on hand-it will be necessary for him to get out at least 600 chicks. Of these onehalf (or 300) are likely to be males; so that at the start he will have but 300 females. The poultryman must count on some deaths by disease and accident. There will be some weak ones that are better off put out of the way. Then he should watch his flock carefully and cull closely, according to the principles laid down in Chapter VII. The man who gets out 600 chicks in the spring will be lucky if he has 200 standard bred pullets in the fall.

\section{USE LEG BANDS.}

Pullets when they are put in the laying pens should be marked with leg bands. It is not necessary to use bands with numbers; plain bands are just as good. It is my personal practice to mark birds hatched in the even years (years that can be divided by two) with a band on the right leg; and birds that are hatched in the odd years (years that cannot be divided by two) with a band on the left leg. In this way I can always tell at a glance just how old a bird is, and never confuse a pullet and a year-old hen.

\section{INCUBATOR OR HEN, WHICH?}

Sooner or later the poultryman must face the question with which this paragraph is headed, and it is my purpose now to help him to answer. In this matter, as in most others, there 
is something to be said on both sides. In favor of the natural method there is first of all economy. It costs at least $\$ 25$ to install an outfit for artificial incubation, and this is an expense that many can ill afford. Chickens brooded by hens have more stamina and are subject to fewer diseases than chickens brooded in any other way. There is no mother for a brood of young chickens than can equal an old hen. Some of the most progressive poultrymen in the country use hens exclusively, setting hundreds of them at a time.

The disadvantage of the natural method is that it is never completely under one's control. Whatever mental qualities a hen may or may not possess, she has a full-grown, large-sized will; and no method has yet been discovered to make a hen sit when she does not want to. To realize the largest profits in poultry, chickens must be hatched early and kept growing from the day they leave the shell. It is not always possible to have a supply of sitting hens on hand. The sitting hen is liable to leave her nest before her task is done, and no amount of persuasion will induce her to return. Sometimes she crushes eggs or young chicks under her clumsy feet. At the best she can bring out but a few chickens at a time. After a while the upto-date poultryman is almost certain to come to the conclusion that he must have an incubator.

The advantage of the artificial method is that it is so completely under one's control. The incubator may be started at any time. The best machines are so adjusted that the element of chance is practically eliminated, and every fertile egg may be incubated. The trouble comes in rearing the chickens. Brooder chickens require much more attention and are more subject to disease than chickens brooded under hens. The per cent of loss is greater. Especially among beginners there is sometimes a "slaughter of the innocents" that is frightful.

To sum up: If one wants early chickens and wants them in quantities and has the time to give to them, he should by all means get an incubator. Otherwise he would best stick to the hen.

\section{GET A GOOD INCUBATOR OR NONE.}

In purchasing an incubator remember that the best is the cheapest. A poor machine is dear at any price. Beware of the home-made incubator. Sometimes they work satisfactorily, but oftener they do not. I know a young man of more than ordinary ingenuity who constructed an incubator from plans that he found in a paper. By visiting the machine at intervals 
during the day and by getting up two or three times a night to trim the lamp or to pull out plugs so that the surplus heat might escape, he was able to keep the temperature somewhere near where it ought to be. But one warm Sunday, while he was at church, the temperature took a leap upward, and when he returned at noon the thermometer registered 120 degrees. As a consequence 180 chickens were prematurely roasted, and nearly three weeks of valuable time lost. The young man has lost confidence in incubators, and now hatches his chickens with hens. An incubator should be bought at least a month before it is to be started on eggs, in order that the operator may become thoroughly familiar with the machine and know how to run it right.

\section{A NATURAL HEN INCUBATOR.}

The work of caring for sitting hens may be greatly reduced by the construction of what I may call a natural hen incubator, the design for which is shown here.

This natural hen incubator may be of any length; but should be two feet deep, two feet high, and divided into com-

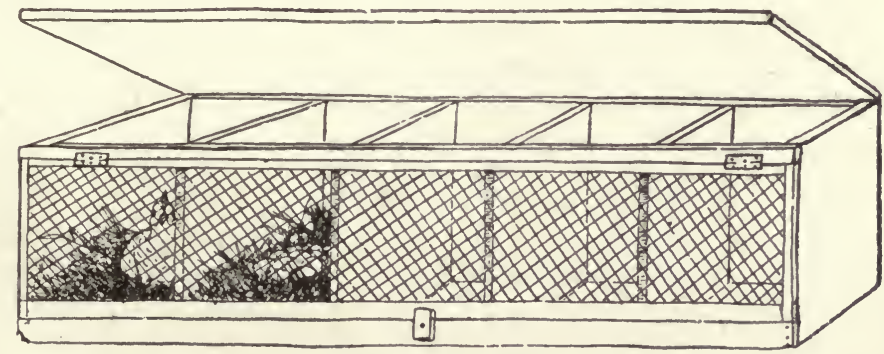

The Natural Hen Incubator.

partments 18 inches wide. Some prefer a door to each compartment, but I find it more convenient to have the doors somewhat longer, so that one may enclose a number of divisions. The top should be hinged at the back, so that it can be lifted up if desired, as shown in the cut; but ordinarily it is shut down. The door front is covered with chicken wire. Each compartment should be in two divisions, so if a hen wishes to leave her nest temporarily she can do so.

If possible, enough hens should be set at one time to utilize all the compartments behind a door. The door should be kept. latched except in the morning when it is opened, the hens taken off, fed and watered and left to dust. In from 10 to 20 
minutes, according to the weather, the hens should be driven back. As the hens are all set at the same time it makes no difference which compartment a hen enters. She will find eggs ready for her.

\section{THE SITTING HEN.}

Where incubation is carried on by the natural method it is important to have a supply of sitting hens on hand in March, April and May, in order that the chicks may be hatched early. While it is true that no method has yet been discovered to make a hen sit at will, it is also true that the instinct may be encouraged. As soon as we understand the philosophy of incubation we may go to work to bring about the desired result. In a state of Nature when does the hen sit? In summer. Why in summer? Because the reproductive instinct has been stimulated by the hot weather. Because she has laid her litter out. Because she has become fat and sluggish. It is evident that if we can reproduce these conditions we can hasten incubation.

Old hens make the best sitters, because they are not so active as young ones. The treatment of hens that are kept for sitters should be radically different from the treatment of hens that are kept for layers. They should be confined more closely and fed differently. Corn should form an important part of their food. As soon as a hen shows symptoms of broodiness she should be encouraged. She should be taken at night and placed in a nest prepared for her in a dark, quiet place. This nest should contain china eggs, and should be covered with a burlap bag to make it dark. The next morning the bag should be removed and the hen let out for food and water. If she goes back it is safe to entrust her with real eggs.

The comfort of a sitting hen should be scrupulously looked after. Before she is placed on the nest she should be thoroughly dusted with some good insect powder and again just before she brings off her brood. She should be taken off the nest, fed and watered and given a chance to dust herself every day. Sitting hens should be fed on whole corn, as that is slowly digested and is a heat-forming food.

\section{TESTING THE EGGS.}

While it is essential that the sitters be kept as quiet as possible, yet it is important that the eggs be tested once or twice 
during the period of incubation. Egg testers can be purchased at a low price from the manufacturers of incubators or at poultry supply stores. Eggs must be tested in a dark room or at night. The first test should be made at the expiration of seven days. If the egg, when looked at in the tester, is clear, it is infertile and should be removed from the nest. If the egg, when looked at, is cloudy or dark, with a well defined air space at the big end, incubation has begun. The water test, described in the next section, should be made on the nineteenth day, and eggs with dead germs in them taken out.

THE WATER TEST.

Where a sitting hen does not have a chance to get out doors, her owner should supply moisture to make good the loss to the eggs by evaporation. Eggs should be sprinkled on the seventh and on the fourteenth day. Remove the hen from the nest and with a whisk broom sprinkle the eggs thoroughly with water of a temperature of 95 degrees. On the nineteenth day the eggs should be given a bath. Fill a pail with water of the temperature of 95 degrees, and after it has become still drop the eggs in it one by one, letting them remain from one to three minutes. If there is a lively chick in the egg in a minute or two it will begin to bob up and down as a float does on the water when a fish is nibbling at the bait below. Take the egg out and put it back in the nest, wiping it with a towel if it is winter, but letting the surplus water remain if it is summer. In case an egg does not show any movement after being in the water three minutes-if it does not "jump"-you might as well throw it away, as it will not incubate. Chicks from eggs treated in this way come out strong and clean and make a surprising growth. 


\section{CHAPTER XI.}

\section{Chicks and Their Care.}

Poultry keeping is not with me a means of livelihood, but is more in the nature of a recreation. It is a matter of personal pride with me, however, to make poultry keeping pay. I do not at present get out my own chicks, but supply eggs to those who have a knack for the business and let them hatch chicks for me and keep them until they are weaned. Then I select what I want in accordance with the principles laid down in Chapter VII. People often wonder how I get such a growth on my chicks after I take them into my hands. The reason is very simple. I select only as many chicks as I have room for and I keep chicks of the same age together. The average poultry keeper gets out altogether too many chicks. There is a temptation when eggs are hatching well to set every hen that is broody or to fill up the incubator just once more. There is plenty of room for the chicks at first, but as they grow older they are crowded and do not do so well as they ought. Then when chicks of different ages are left together, there is too much "rough house" for the younger ones and they become stunted. If you want fine birds get out only as many chicks as you have room for, divide them into small flocks, and keep chicks of the same age by themselves.

\section{WHY NOT INSTALL A BROODER?}

Even where an incubator is not employed a brooder may be installed to good advantage. I know a man who gets out in the neighborhood of 1,000 chicks every spring-hatching them all under hens and brooding them in brooders. I am as great an admirer of the American hen as any other man, but I confess that her conduct as a mother is often not such as to impress me with an exalted opinion of her mentality.

The best brooder, in my opinion, is one built for 100 chicks, and costing about $\$ 12$, just as the best incubator is one built for 200 eggs or thereabouts. The out-door brooder is not generally satisfactory, as it is difficult to keep chicks warm enough in it when the temperature ranges, low. The brooder should we placed in a brooder house, and there is no better brooder house in my opinion than the colony-community house described in Chapter II. 
Be sure to set the brooder where the sun will not shine on it, in installing it in a house, and do not put more than 60 chicks in a 100-chick brooder.

\section{REMOVING CHICKS TO BROODER.}

We will now assume that the period of incubation is completed, and that the chicks are ready to be removed from the nest. It is 24 hours at least since the last chicks broke the shell, and may be 48 hours since the first hardy pioneer made his entrance into our sinful world. I assume that two or three times while the chicks were hatching you gently lifted up the mother hen and removed the fragments of broken egg shell from the nest.

And now comes the most important and in some ways the most disagreeable part of the whole business-the transfer of the chicks from the nest to the brooder, which may be some distance away. You cannot choose your day-it may be cold or it may be warm-but you can choose the warmest part of it for your purpose. Better take your wife with you, if you are fortunate enough to have one. Take a shallow basket, such as is used for marketing, and line the bottom with a piece of old woolen blanket, which has previously been warmed. Over this lay another piece of warmed blanket, to put over the chickens when they-are placed in the basket.

As each chicken is taken out from under the hen anoint its head lightly with lard or vaseline, to kill head lice, and place it quickly in the basket. When the basket is full take the chicks to the brooder house and place them in the hover, which has been brought to a temperature of 100 degrees.

If 'you are a man of tender sensibilities you will feel as if you were a kidnapper or a manstealer when you take the chicks away from their mother. You will feel, as one man expressed it to me, "to mean to look a hen in the face." But, fortunately, the hen does not suffer long-she soon forgets. Place her - in a bright, sunny pen where there are other hens and a male, supply her with more varied food than she has been accustomed to during the period of incubation, and in a few days she will be scratching and singing as merily as of yore.

TWO SECRETS OF SUCCESS-HEAT AND FEEDING.

The two great secrets of success in raising brooder chicks are proper heat and proper feeding. The heat should come from overhead, as this is the most natural method, and should be hot air. Bear in mind that the young chick needs a great 
deal of heat. He has come from a warm place-the temperature of his mother's body being 103 degrees. For the first two or three days the temperature in the brooder should be 95 degrees; then it may be gradually lowered, as the chicks grow. until it drops to 80 degrees if the weather is warm and pleasant. "The best rule to follow is to observe the chicks.

they arrange themselves at the edge of the brooder, and separate, by spreading out, the heat will be just what they desire. If too cool they will come closely together and crowd. Many operators have left their chicks apparently contented at night, only to find in the morning some of them dead under the brooder, because the heat lowered and the chicks trampled among themselves in the effort to secure more warmth, and this, too, when (to the operator) there seemed to be sufficient."

\section{CARE OF THE BROODER.}

The brooder is to be the home of the chicks until they are at least six weeks old. It is a good idea to keep the brooder in the brooder house until August, and then on cold, wet days which we sometimes have in summer give the chicks a little heat. The floor of the brooder should be kept sprinkled with sand, and should be cleaned every morning. The floor of the brooder house should also be kept covered with clean sand, and the windows should be opened every warm and sunny day. There is no hurry to get the chicks out on the ground; indeed, it is better for them to spend the first four weeks of their lives indoors.

The brooder should be enclosed with a low fence of boards for the first few days, so that the chicks cannot get far away. They should be given their first feeds in the brooder and watered there, but in a little while the feed tray and fountain may be placed outside the brooder, but close to it. Grit of some kind should be supplied.

\section{HOW TO FEED BROODER CHICKS.}

My method of feeding brooder chicks is as follows: The first week or ten days I feed rolled oats and nothing else-just the same kind of rolled oats that I use on my own table. I feed them dry. I feed them in little troughs made for the purpose, and keep oats before the chicks all the time. Every day or two I take the troughs and empty the oats remaining in them into the hens' dish, and brush out the troughs with a whisk broom. It may seem extravagant to feed rolled oats at 
five cents a pound, but I believe the foundation of a chick's constitution and future growth is laid in the first few weeks of its life, and it is cheaper in the end to feed as I do and have the chicks live and thrive than to feed something else and have them stunted and die.

At the end of a week or ten days I begin to introduce a little variety. I take wheat and cracked corn-one part wheat to two parts corn-and feed a small quantity of this in place of the rolled oats. I increase the quantity of wheat and corn from day to day and decrease the quantity of rolled oats, so that when the chicks are a month old I have weaned them from the rolled oats and am feeding them on whole wheat and cracked corn. When the chicks are ten days old I begin to give them green food-a little at first, but increasing in amount from day to day. I feed onion tops, cabbage chopped fine, clover tips, or if I can get nothing better a potato baked and cut in two.

give meat in small quantities two or three times a week. Into a kettle of boiling water I put a piece of cheap meat or soup bone with considerable meat adhering, and keep it there until well cooked. Then I pour off the liquid and take the meat and chop it into fine bits, or grind up the bone in my bone cutter, and throw a little to the chicks. They eat it greedily. I put a little salt in the water so that it will get into the fibres of the meat, because I think chicks need a certain amount of salt.

I feed in this way until the chicks are "feathered out," when I begin to feed them much as I do my hens-a warm mash, and two or three feeds of grain a day. Until my chicks are "feathered out" I keep food before them all the time, letting them help themselves when they will. I ought to add that I am careful to keep cool, fresh water before them from the very first, and also charcoal and grit.

BROODER CHICKS-WHAT ANOTHER MAN THINKS.

Writes C. A. Stone in the Poultry Standard: "I generally leave the chicks in the incubator about 24 hours after they are practically through hatching, and meanwhile heat a brooder to 95 degrees for about every 50 or 60 chicks. At first I strew the front of the brooder with fine grit, and then give them bread crumbs or wheat screenings or Cyphers Chick Food for their first feed-just what they will eat up clean-and give them all the water they want. I generally feed about five times a day for the first two or three days, and gradually drop off to three feeds at three weeks. However, after the first two or three days I scatter their feed in a little litter, and make them 
hustle for it. Nothing under the sun will kill young chicks quicker than stuffing them and letting them stand around. I also give them green food of some sort and every two or three days a mash containing 8 per cent. or 10 per cent. of meat meal. But above all things keep them hustling.

"After the first two days I drop the temperature to 90 degrees. I aim to get the heat down to 80 degrees in the first week and a half and to 70 degrees in eight or ten days more. As near as I can I mean to drop the temperature about one degree a day until 70 is reached.

"For myself I use outdoor brooders mostly, and while we cannot maintain a uniform heat, by close watching we can keep a comparatively even temperature, as my experience is that after a chick has been chilled or over-heated it is poor property. I believe in getting them on the ground as soon as possible after the chicks learn to run in and out of the warm part of the brooder, and very frequently am obliged to shovel snow out of the brooder runs. But a chick will stand a lot of cold if he keeps on the move. Of course they must be watched closely in cold weather and if they show signs of huddling shut in until thoroughly warmed.

"Some of my best flocks have been raised on wheat screenings alone, but I have had good success with some of the prepared chick foods. We must be governed by the season of year in moving to the cool brooder, as early chicks must be supplied with heat a long time; but along in the latter part of April I get them hardened to go without heat in about three weeks. At this age they are practically past the danger point, and if kept free from lice and given proper care will live and thrive."

\section{WHEN CHICKS ARE RAISED IN THE GOOD OLD WAY.}

There are many who prefer the "good old way" of brooding by hens, and to them recommend the following from the pen of my good friend, Mr. A. F. Hunter: "For the first 24 hours after hatching chicks do not need food, as the portion of yolk that has just been taken into the abdomen has not been fully digested; and then, too, the chick should get accustomed to the fact that he has 'just been borned' before his little crop is started on its seldom empty journey through life. When the hatch comes off let the little fellows have a drink of pure fresh water (not too cold); this invigorates them and helps clear the digestive organs of waste from digested yolk. 
"The first food should be bread crumbs and hard boiled egg. or johnnycake. To each pint of food add a sprinkling of chicken grit. The food for the first few weeks should be johnnycake, rolled oats, coarse oatmeal and bread or cracker crumbs. A little well cooked meat finely minced three times a week, and a liberal supply of fresh green food, grit, charcoal and pure water are essential to health. When the chicks get to be six weeks old they should have a cooked mash for supper six nights in the rveek. For other food they should have hulled oats, wheat and a little cracked corn-fresh green food alwais

"From the first have a litter of chaff or cut clover and sand for the chicks to scratch in ; exercise is essential to good digestion. Give them sunny quarters, and provide a shelter in case the sun is too hot, and for protection in stormy weather. When warm weather comes be sure that they can have plenty of freedom and exercise on the green bosom of 'Old Mother Earth.' Keep them busy, happy and hungry. Be careful not to overfeed. If you must coop them up, make the coops large enough to give them plenty of room to exercise and grow. Change the location of such coops often, to give them fresh ground to run on."

\section{WHEN TO HATCH CHICKS.}

Chicks of the Asiatic breeds should be hatched in March, chicks of the American breeds in April, and chicks of the Mediterranean breeds in May for winter egg production. Poultrymen who want eggs all the year round will do well to keep getting out chicks from March to June and then start in again in September. Josh Billings quaintly says that "the best time tew set a hen iz when she wants tew set," and the man who has the facilities for taking care of them will find that chicks hatched at almost any season of the year will not come: in amiss. I have known White Wyandotte pullets of my strain, hatched in August, to begin laying in January, when in the same pen were pullets of other breeds hatched months before that had not begun to lay. 


\section{CHAPTER XII.}

\section{Some of the More Common Poultry Diseases.}

There are comparatively few diseases that need give the poultry keeper much alarm. I have heard it said that our domestic fowls are subject to as many diseases as human beings. But if this is so (which I greatly doubt) many of these diseases are so rare that they need not be taken into consideration. In this chapter I shall mention only the more common ailments-and give some rules for their treatment.

\section{HOW TO DISCOVER THE BEGINNINGS OF SICKNESS}

There are four ways by which the poultryman may discover the beginnings of sickness. 1. General appearance. A fowl in health is alert and active, plumage smooth, comb red, eye bright and clear, appetite good. A sick fowl is generally dumpish, plumage rough, comb pale or purple, appetite poor. 2. Respiration. Certain kinds of disease affect the respiratory organs and manifest themselves in the breathing. The best time to detect a disease of this sort is after the birds have gone to roost. If the birds on the roost sneeze from time to time, if the breathing is labored, if there is a rattling, bubbling or snoring sound, something is wrong and needs attention. 3 . Excrement. The excrement is a pretty good index of the health of a hen. Where the bird is in perfect health the excrement is dark green in color, tipped with white, somewhat moist. Where the excrement is soft and watery the digestion is disturbed. Where it is light green in color there is danger of serious trouble. If upon examination the excrement shows that considerable food is passing through undigested, the bird needs to be supplied with grit. 4. Odor. Some kinds of disease-especially roup-are accompanied by an offensive odor, and can at once be detected by the smell.

\section{SEGREGATE SICK BIRDS.}

I would advise all poultrymen to fit up a small building for a hospital, to which all sick fowls may at once be removed. In the case of a contagious disease this is especially important, for the sick bird if allowed to remain with the rest may com- 
municate the disease to the whole flock. Even where the disease is not serious, the patient is much better off if by herself. The hospital should be kept scrupulously clean, and should be thoroughly disinfected after a bird has been confined in it affected with an serious trouble.

\section{DISEASES OF CHICKS.}

Lice.-In the chapter on "Chicks and 'Their Care." I have warned the breeder to be on the lookout for lice. I repeat the warning here. More chicks are sacrificed in this way than in any other. Even if the chick is not literally eaten alive it; vitality is often so much reduced that it readily falls a prey to disease. It is never safe to give up the warfare against lice.

Cramps and Rheumatisn.-Many persons who get out early chicks have no proper facilities for handling them. Perhaps there is snow on the ground and the chicks cannot get out of doors, so they are left on a board floor or in a crowded brooder, and in a few days their legs begin to draw up, the joints become red and swollen, and the little things die. When cramps and rheumatism get among the chicks transfer at once to dry and roomy quarters where their ieet can get on the earth, give green food in variety, and rub their legs with witch hazel. Sprinkle chaff about so that the chicks will have to scratch for their food. Reduce the number of chicks in the trooder, if crowded. Give as much baking soda as you can get on the tip of the handle of a teaspoon, in a quart of water.

Leg Weakness.-Where young fowls are forced forward for broilers or soft roasters they are apt to develop leg weakness, the nature of which is sufficiently explained by the name. The bird walks unsteadily, lurching from side to side, and sometimes sits when eating its food. "In all cases give cooling focd, such as bran, barley, rice, green food, skim milk or buttermilk and vegetables. Avnid condiments, meat and stimulating rations of all kinds."

Gapes.- "Gapes are caused by small worms which attach themselves to the membranes of the windpipe of the chick. A piece of camphor about the size of a grain of wheat, daily, and 10 drops of camphor or turpentine to each pint of drinking water, is a favorite and effective remedy." The tip of a feather dipped in turpentine and run down the chick's throat will dislodge the parasite. 


\section{DIARRHOEA OR EN'TERITIS.}

Feathering out is a very trying period in the life of a chick, corresponding to teething in the life of a child. There is a double tax upon the chick's system: the ordinary demands of growth must be met, and the little body must be covered with feathers. It is a time when even the most careful poultryman must expect some fatalities, and the careless or lazy poultryman must not be surprised to see his flock melt away like snow before the sun in springtime. When the poultryman goes to feed his chicks he notices one or two, perhaps more, standing around in a listless, dejected way, wings drooping or outspread, with possibly a white threadlike substance which has just exuded from the bowels, clinging to the fluff around the vent. The chick may throw up its head and gape. In a few hours it will be dead. Its digestive system is deranged, and it is suffering from what is known as Diarrhoea or Enteritis.

It is better, far better, to avoid this disease than to attempt to cure it. The poultryman should realize what a critical period feathering out is, and strive to meet it. Especially should he be careful about what he feeds his chicks, making no sudden changes in their bill of fare. Nor should he let them become chilled or get drenched in a shower. If, in spite of all precautions, chicken cholera makes its appearance, the house and brooders should be thoroughly cleaned, all drinking vessels scalded, and air-slacked lime sprinkled lightly about. Some good remedies are as follows: "Boiled rice upon which has been sprinkled a little cinnamon, lime-water to drink: boiled milk and dry bran." In mild cases add one or two drams of sulphate of iron to a pint of drinking water. In very serious cases where the diarrhoea is accompanied by pain: fever or bloody discharges, give $1 / 8$ grain powdered opium and two grains subnitrate of bismuth every four hours.

\section{COLDS AND BRONCHITIS.}

Fowls are very susceptible to colds. The reason is, I suppose, that they are subjected to great changes of temperature. Poultry houses are so built that the sun shines full upon them, and at midday even in winter the interior is often very warm. It is generally when the temperature is highest that the fowls are working the hardest. The conditions are analogous to what they would be were a man obliged to wear a heavy fur coat all the time night and day and exercise in a room where 
the mercury was at 70 degrees, and then sleep in a room where it fell below zero. Such extremes would affect the hardiest constitution. Colds would not be nearly so common if poultry keepers would open the windows in their houses every day in winter when the sun shines, and keep them open from 11 o'clock in the morning until 4 in the afternoon.

The symptoms of a cold are sneezing, bubbling at the nose watery eye and perhaps diarrhoea. Colds generally cure themselves without any especial treatment, but there is always a possibility that colds if neglected may run into something serious. Ten drops of aconite in two quarts of drinking water is a simple and good remedy when administered in season. For mature birds a one-grain quinine pill or one Laxative Bromo Quinine Tablet, given each night for two or three nights, will generally do the business. The tablet should be greased, so that it will slip down easily. Here is a home-made pill that is effective: Take equal parts cayenne pepper, sulphate of quinine and sulphate of iron-mix together with extract gentian; mould into pellets about the size of a pea, and give one every 24 hours. (This is not a bad remedy for human beings, doubling or trebling the dose.) Bronchitis is a bad cold accompanied by coughing or rattling in the throat. The treatment is the same as for a common cold.

\section{THE DREAD SCOURGE-ROUP.}

Roup is now believed to be a bacterial disease-that is, disseminated by means of germs-and not as was formerly thought the result of a neglected cold. If this is so, roup can only be introduced from outside; it cannot originate within. But it can be introduced in many ways: by means of a bird bought of a careless or irresponsible breeder, by means of excrement brought on the feet, by means of germs or spores floating in the air. The seeds of roup will remain for years: so that it is never safe to buy an old henhouse, unless you are absolutely sure the disease has never been within its svalls. Catarrh is often mistaken for roup, but in catarrh the peculiar smell that goes with roup is not present.

Each new case as it comes up should be isolated. Roup may be discovered in two ways. A roupy bird generally sleeps with her head under her wing, and by going through the pen at night with a lantern one may easily find her. The other way in which a roupy bird may be told is by a slight moisture in the 
lower corner of her eye, or perhaps little bubbles there. In well developed cases there is a roup smell that once known can never be mistaken. All suspects, should be quarantined, fed lightly on a warm mash in which there is little ginger, and given their drinking water in disinfected vessels. Two or three times a day spray their nostrils and mouths with the following solution: Extract witch hazel, four tablespoonfuls; water, two tablespoonfuls; carbolic acid, three drops. Use an atomizer, and squeeze the bulb five times for each nostril and twice for the mouth. The bird will often recover under this treatment.

\section{THE KEROSENE TREATMEN'T FOR ROUP.}

It is a question whether it pays to doctor a severe case of the roup. Even if the bird lives she will be worthless as a breeder, and it will be some time before she comes into shape to lay again. A sharp hatchet is about the best cure for roup that I know of. Still, if you want to give the bird a chance: try the kerosene treatment-in my judgment, the simplest and best treatment known. Take a wooden pail and fill it twothirds full of water, and then pour on one-half cupful of oil. Take bird by the feet and dip her head under water, letting it stay there while you count three. Wipe the bird well with a piece of soft cloth, and return to the hospital. Some of the kerosene will percolate through the outer skin, and some will be taken into the bird's mouth as she tries to clean up her feathers. The kerosene uniting with the pus coagulates it, and in a few days the mass scales off, leaving the tongue pink and clean. The patient is still weak, and should be kept in the hospital a while longer before she is returned to her mates.

The best diet in roup is bread moistened with milk. The throat is so tender that hard food cannot be swallowed. I had a roupy bird that I had kerosened. She seemed to be doing well, but had no appetite. I tried to tempt her with warm mash, but to no avail. I put her out doors to see if the warm sunshine would not hasten her cure. Soon I noticed her about the sink spout picking up the crumbs that ran down when my wife washed the dishes. I took the hint and gave her bread soaked in milk. She ate heartily and made a fine recovery.

I would advise the poultryman to keep some standard roup remedy on hand, and when the disease breaks out to use the 
medicine according to directions. In purchasing a remedy select one that can be administered in the food or water, and do not bother with pills or powders that you have to give to the individual bird.

\section{CHOLERA.}

Next to roup the most serious disease that the poultryman is called upon to combat is cholera. Cholera would be even more serious than roup were it as common. It is a disease of damp, hot weather, and disappears quickly in a dry time or upon the approach of frost. Like roup cholera is transmitted by means of germs, and it affects not only the domestic fowls but some of the wild birds as well.

Approach of cholera is generally heralded by loss of appetite on the part of the birds in a flock. The first definite symptom is discoloration of the urates, but in cholera the urates are at first yellow, changing as the disease progresses to green. Diarrhoea sets in. The bird separates itself from the rest. stands in a dejected attitude with roughened plumage, and seems asleep. The crop is extremely thirsty. Great weakness follows, and in a short time the bird dies.

No satisfactory remedy for cholera has been discovered. Remove the infected birds to a place by themselves, and when one dies burn the body or bury it so deep that dogs or foxes cannot dig it up. Thoroughly clean up the house and yards, and bury the excrement. Sprinkle the floor and yards with a solution made of one pint carbolic acid and three gallons warm water, applied with a common watering pot.

\section{DISEASES OF THE LIVER.}

Nine-tenths of the diseases that afflict laying stock come from derangements of the digestive organs and of the liver.' In order to get eggs it is necessary to feed highly, and this reacts upon the health. The poultryman must expect every now. and then to lose a hen. Fortunately the value of the individual hen is not great, and he must not be disheartened if he finds one dead from time to time. When hens begin to drop offas they will in the spring - the poultryman must immediately begin to revise his methods. He must feed a less stimulating ration, give more green food, and compel his hens to take exercise. A teaspoonful of sulphate magnesia to each pint drinking water, given for a week, then followed for a month 
by adding one-fourth grain sulphate strychnia to two quarts water, is a good tonic. Where the liver is affected, as will be shown by the color of the comb-purple, becoming dark and even black-give a teaspoonful of castor oil once a day, instead of the sulphate of magnesia and strychnia.

\section{CROP BOUND.}

This condition is sufficiently described by the name. The bird mopes around, dejected in appearance, and upon examination her crop feels as if she had swallowed a baseball. Give her a tablespoonful of castor oil and put her in a pen by herself for twelve hours, when the mass may pass away. If it does not it will be necessary to operate. You will need someone to assist you. With a sharp knife make a longitudinal incision three-quarters of an inch in length in the upper part of the crop, first plucking out any feathers that may be in the way. Take a small hardwood skewer, such as butchers use, and begin to remove the contents of the crop. It will take some time. To make sure that everything has been removed and that there is no obstruction insert your little finger into the outlet of the crop, where the food passes into the gizzard. Rinse out the crop with warm water. Sew up the opening in the crop with silk thread, making each stitch by itself, tying and cutting the thread before making another. Do the same thing to the outside skin. Put the bird back in the pen by herself, and feed lightly on soft food for a few days.

\section{SCALY LEGS.}

"Scaly legs are the work of a minute parasite, and the trouble is contagious. There are quite a number of remedies, but more depends upon care for a few weeks than anything else. Take three tablespoonfuls of lard and add to it two tablespoonfuls of kerosene oil and one of glycerine: then drop into the mixture (which should be mixed warm, not hot) two drops of carbolic acid. Wash the legs of the fowl and wipe dry, rub on the mixture very thickly, having it warm, not overlooking any part. Repeat this twice a week for two or three weeks and the legs will soon hecome clean and perfectly smonth."

\section{A GOOD TONIC.}

There are times when a good tonic is of great value in the poultry yard. After a long, cold winter or when disease makes 
its appearance and it is desirable to reinforce the health of the fowls, a good tonic should be given. Douglas Mixture is one of the best, and is used by poultrymen everywhere. It is made as follows:

Sulphate of iron, 8 oz.

Sulphuric acid, $1 / 2$ oz.

Water, 1 gal.

Put into a bottle or jug one gallon water, add the sulphate of iron; as soon as the iron is dissolved add the acid. When the mixture is clear it is ready for use. Dose, a tablespoonful to every quart of drinking water. The drinking vessels while using this tonic, must be glass or glazed earthenware.

\section{MOULTING.}

Moulting is not a disease, in the sense that it is something abnormal or unnatural; but it is a disease in the sense that it is a state of discomfort or dis-ease. For best results in egg production birds should be helped through the moult, and the time should be made as brief as possible.

Remove all males from the flock as soon as moulting begins, for it is best for both the males and females to be separated at this time. Feed about as usual, only be sure that plenty of meat or green ground bone is given in the daily ration, and that plenty of green food is always at hand. Three times a week in dry, bright weather put a tablespoonful of flowers of sulphur in the mash for every fifty fowls, and on alternate days a tablespoonful of carbonate of iron. Do not give the carbonate of iron to white fowls, for it will give the feathers a creamy or brassy tinge. If this treatment is kept up during the entire moult the birds will get through easily: as there will be no loss of strength, nor will any of them hang in the moult, but keep on until completed.

\section{EGG EATING: HOW TO PREVENT IT.}

Egg eating is a vice that is much easier to prevent than to cure. Where the eggs are gathered at frequent intervals, where the hens are supplied with plenty of material for making shells, where the hens are kept busy when not on the nests, egg eating is practically unknown.

The only sure cure for egg eating is the hatchet. Before this is applied, however, an effort should be made to stop the vice. Two or more china eggs should be placed in each nest: 
and plenty of these eggs strewn in the litter upon the floor. Then pare the upper beak of the guilty bird until it shows signs of bleeding, so that when she strikes the china eggs the pain will make her stop. Generally this will effect a cure. Something can be done by having the nests in a dark place and so arranged that it is difficult for the hen to get at the egg after she has laid. A nail keg makes an excellent nest for egg-eating hens. I have known men to make a double-decked nest, so that the egg after being laid would drop through a small hole into the receptacle below. Raw salt pork, chopped fine, is recommended for egg-eating hens; but the best thing is never to allow them to contract the habit.

Mr. S. D. Fox, to whom I have several times referred, has a method of breaking hens of egg eating as novel as it is efficacious. "My hens got to eating eggs one spring," he says, "and I went to work to cure them. I got an egg, chipped off one end and took out the yolk and white. Then I filled up the egg with soft soap, sprinkled in a good stiff dose of cayenne pepper, stuck on the end with white court plaster, and dropped the egg on the hen house floor. They ate that egg. The next day I gave 'em another. They ate that. The next day I gave 'em a third. They didn't eat that, and they never ate another so far as I know. Didn't like the flavor, I guess. Hurt 'em? Wall, no, I never see that it did. Might have cleaned 'em out a little-soft soap is good for that, you know-but it didn't rumple a feather, so far as I could see." 


\section{CHAPTER XIII.}

\section{Products and By-Products.}

Producing the eggs and rearing the chicks forms but a part, and perhaps the smallest part, of the poultryman's business. In order to make money he must market the product to the best advantage. It is here, I am convinced, that the majority of poultrymen fail. They are not good business men. They work hard enough, but do not calculate closely and do not sell at the right time or at the right place. In these days when competition is so close and the margin for profit so narrow, the difference between profit and loss in the poultry business may consist in the manner in which the product is put on the market.

The man who keeps but a few hens and does not make poultry raising his principal occupation, will probably do better to sell his eggs and poultry to his regular grocer than to hunt up private customers. It is true that he may receive a cent or two a dozen more if he sells at houses, but this is more than offset by the loss in time. The grocer is not so particular about his eggs, as long as they are fresh, as is the private customer, and will take eggs of all sizes and colors. It is true he does not wish to pay in cash, but the profit on his goods is about the only profit he makes on the transaction; for the grocer is often compelled to sell eggs for just what he gave for them. The grocers are the great buyers of eggs throughout the land.

The man who keeps hens on a larger scale, and who wants to make the most out of the business with the least trouble: will do well to make an arrangement with a city grocer to ship him a certain number of cases each week throughout the year. The poultryman should go to the city and see the grocer personally. The chances are he will get an order. This is far more profitable than selling to the local grocer. In the town where I live I have seldom known eggs to go above 30 cents a dozen, and they remain at this figure but a short time, while in the cities to the south of us they sometimes sell as high as 45 or 50 cents.

The poultryman who produces a gilt-edged product can often market to private customers to advantage. The hotels 
will take a limited number of fancy fresh eggs. They do not take so many as one would think, because in cooking they use cold storage eggs. Clubs are góod customers, and will pay a fancy price for a fancy article. Druggists use a large number of brown eggs in connection with their soda trade, and will often pay a good price for fresh eggs of good color. There are private families that will gladly pay the poultryman the same price they have to pay for eggs at the store, and pay in cash. The advantage of having private customers is, that one can sell them beside eggs, poultry, vegetables, cream, berries and other products of the farm and garden.

\section{PRESERVING EGGS.}

There is always a time in spring when eggs are very cheap. The poultryman can add to his profits and at the same time relieve the congestion in the market by improving this opportunity to lay down a supply of eggs for home consumption for the year to come. I do not believe in selling these preserved eggs for fresh eggs, but there is no reason why the poultryman should not use them in his own family. Neither is there any objection to selling them in the fall, provided they are sold for just what they are-preserved eggs and not fresh eggs. I know a man who every spring when eggs are cheap lays down 400 dozen, and then about Thanksgiving sells them for a little less per dozen than is asked for the best fresh eggs: clearing up about $\$ 60$ by the deal. A profit of 150 per cent. in six months leaves Wall Street out of sight. There are two absolutely sure methods of keeping eggs, both of which I print. These methods are the soluble glass and the lime water methods. Of the two I prefer the soluble glass, as cleaner and more convenient. Bear in mind, however, that no method under the sun will keep eggs fresh which are not fresh when laid down!

\section{LIME WATER METHOD.}

Slack four pounds lime, and then add four pounds salt. stirring well together. Add eight gallons water. Stir and leave to settle. The next day stir again. After the mixture has settled the second time draw off or carefully dip out the clear liquid. Take two ounces each of baking soda, cream of tartar, saltpetre, and a little alum. Pulverize and mix, and dissolve in two quarts boiling water. Add this to the lime water. Put the eggs in a stone jar, small end down, one layer 
on top of another, and pour on the solution. Set the jar away in a cool place. This process has been secret in the past, and the recipe has been widely sold for $\$ 5$. 'The method is quite satisfactory, although not so good as the method of preserving in soluble glass, as the eggs are liable to have a somewhat limy taste.

\section{SOLUBLE GLASS METHOD.}

Soluble glass, or sodium silicate, is a liquid of a rather smooth, slippery consistency, readily soluble in water. It is used by physicians for coating bandages, where it is desired to protect the injured part from the air, and may be obtained through any druggist at a cost of about 75 cents a gallon. For preserving eggs use one quart soluble glass to about 10 quarts pure water. Put the eggs in a stone jar, small end down, one layer on top of another until the jar is filled, then pour on the solution. If the specific gravity of the solution is greater than that of the eggs, as is sometimes the case, add water until the eggs will just sink.

\section{SALICYLIC ACID AND COLD STORAGE.}

The West Virginia Agricultural Experiment Station has been studying methods of preserving eggs, and finds that the treatment with salicylic acid followed by cold storage is quite efficacious. The station does not claim that the method has passed the experimental stage, and does not advise anyone to use it except in an experimental way. It is worth trying, and is as follows: "Submerge the fresh eggs for five or ten minutes in a solution of one ounce of salicylic acid in one quart of strong alcohol, and immediately on removing the eggs from the solution, and while they are still wet, wrap them in sterilized cotton and store in a box or barrel in a dry room, the temperature of which does not go above 60 degrees Fahrenheit."

\section{WOOD ASHES OR SAL'T.}

There are many, however, who desire a simpler method than any of these described, and to such I would recommend cither wood ashes or salt. Wood ashes are excellent. Experiments conducted by the National Agricultural School in Germany shows that eggs may be kept a year packed in wood ashes, with a loss of only 20 per cent. Wood ashes are cleanly. convenient and always at hand. Salt also is good. Use a grade of salt a little coarser than table salt-what is called 
coarse-fine salt. Pack the eggs in a stone jar. Put in first a layer of salt, then a layer of eggs, and so on until the jar is filled. Stand the eggs upon the small ends, and do not let them touch. Cover them completely with salt. Set the jar in a cool place. I have known eggs packed in this way to keep a year, and to be as good at the end of that time for cooking as if laid but a few days before.

\section{POULTRY MANURE-A VALUABLE BY-PRODUCT}

Poultry manure is an exceedingly valuable by-product. It is a highly stimulating manure. It is also a rich plant food. Poultry manure is more than twice as valuable as sheep or hog manure, and more than three times as valuable as ordinary stable manure, as the following table will show:

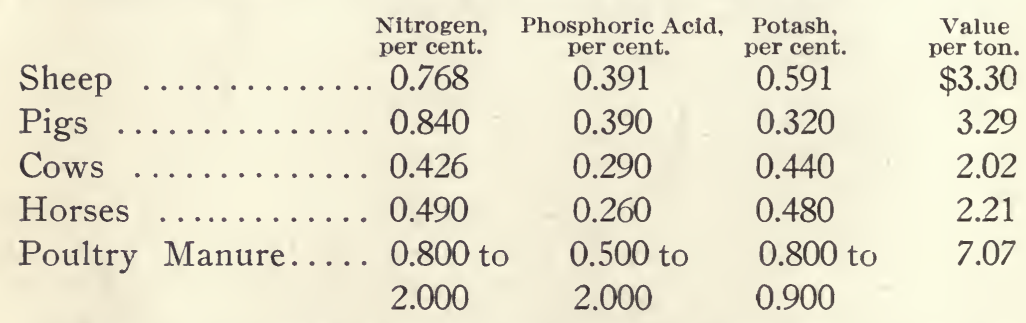

Poultry manure is so powerful that great care must be taken in applying it. It should never be allowed to come into direct contact with the roots of the growing plant. When applied in the hill it should be well mixed with the'soil.

Poultry manure supplies nitrogen in large quantities in the form of ammonia, but ammonia being a highly volatile product is rapidly dissipated. The problem of the poultrymen, therefore, in dealing with hen manure is to find some substance that will fix the ammonia. Sifted earth is not good, for it is apt to contain bacteria which act destructively on the ammonia compounds. Wood ashes, are worse than nothing. for they do not hold ammonia, but drive it off by their caustic alkaline properties.

The best thing I have found to preserve the ammonia in hen manure is gypsum or land plaster, which may be bought for 50 cents per 100 pounds. Scatter a few handfuls of plaster over the droppings before you remove them in the morning, and see that it is thoroughly incorporated. The result is a compound as valuable as any commercial fertilizer. The droppings from a fowl in one year, when treated in this way: are worth one-half what it costs to feed her. 


\section{CHAPTER XIV.}

\section{The End of the Two Hundred Egg Hen.}

The poultryman who keeps from 200 to 500 head of laying stock will have a good deal of poultry to dispose of, especially if he follows my advice in this book to keep pullets, principally, for layers. It will be quite a problem to dispose of this stock to the best advantage. In passing I would remark that the poultryman should keep his own table well supplied. Plump and juicy broilers and roasters are just as good for him as they are for anyone else. There is no reason why the poultryman's table should not rejoice once a week with broilers and roasters. During the summer there is in most towns a good market for poultry. The poultryman should steadily cull from his flock, and about moulting time have a grand "round up," selling the fowls for what they will bring-except those he wishes to keep over for breeders. Quite a number of live cockerels may be disposed of among the farmers in the fall if the poultryman keeps a popular breed and will sell for a fair price.

\section{KILLING AND DRESSING FOWLS FOR MARKE'T.}

1. Take the bird from the roost at night, thirty-six hours before it is to be killed, and shut it up in comfortable quarters. The next morning give it a good breakfast, but nothing more to eat after this until it is killed. Let it have all the water it will drink. The water will add greatly to the fowl's comfort and assist in evacuating the bowels. The' confinement is for the purpose of having the fowl at hand and of emptying the crop.

2. Suspend the fowl by the feet at a convenient height with a soft cord, the upper end of which is secured to a hook or nail in the ceiling or beam overhead.

3. Lock the wings together behind the back, to prevent flapping. Do this carefully, so that they will not be dislocated.

4. Take the tip of the wings in the left hand, and with the right strike the fowl a smart blow on the head with a stick or cudgel. Strike hard enough to produce concussion of the brain and unconsciousness. 
5. Grasp the fowl by the comb or by the feathers at the back of the head with the left hand and with the right insert the blade of a sharp knife in the neck just back of the ear lobe: on the under side of the neck bone and parallel with it. Run the blade clear through the neck. When you withdraw the blade twist it to right angles with the neck bone, severing the artery in the throat, and causing the blood to flow profusely.

6. Begin to pluck immediately. Pluck up the breast and sides to tail. Remove tail feathers. Unlock the wings, and strip them of long feathers. Remove feathers from around vent, pluck the feathers from back. Finish plucking. If done quickly the feathers will come out easily and the skin will not be torn. The bird should be entirely denuded of feathers in ten minutes. In case rents are made sew them up neatly with white thread.

7. If the fowl is to be drawn, with a sharp knife cut a slit about an inch long back of the vent and parallel with it; through which insert index finger, hooking it into the intestines. Remove intestines. The lower end of the intestines and the egg sac may be removed by enlarging the slit in the shape of a half circle, until it joins the ends of the vent. This will make a round hole about the size of a silver half dollar. After removing the intestines cut off the fowl's head, then draw back the skin and take off about an inch of the neck bone, pull the skin forward and tie.

8. For the Boston and New England markets the poultry should be picked perfectly clean. For the New York markets the tip feathers of the wings are left on. Do not singe the Fodies for the purpose of removing any down or hair, as the heat from the flame will give them an oily and unsightly appearance.

9. Plumping is recommended by some dealers, and consists in dipping the carcass as soon as thoroughly picked for ten seconds in water nearly or quite boiling hot, and then immediately into ice-cold water. This makes the meat look plump and fat, considerably improving its appearance.

10. The laws of Massachusetts and New York do not require poultry to be drawn. In the former State, however, the crop must be drawn if there is food in it at the time of killing. Custom, which is quite as potent as statute law, requires that poultry marketed in Massachusetts be drawn, 
and carefully drawn poultry will sell so much more readily and for so much better prices that it pays well to comply with this demand.

\section{TO SCALD A FOWL.}

Where the fowl is to be eaten at home, or where it is sold for immediate consumption, many prefer to remove the feathers by scalding. There is a right and a wrong way to do this. The right way is as follows: Kill in the manner described in preceding section. After the blood has stopped dripping from the wound take a wooden pail, or some other receptacle, fill it three-fourths full of boiling water, and into this pour a pint of cold water to reduce the temperature a little below the boiling point. Take the fowl by the neck and legs and dip it into the water twice-once with the breast downward and once with the back-getting it in and out of the water as quickly as possible. Hang the fowl up again, and begin to pluck. When the feathers have been removed and the intestines drawn, dip out two quarts of water from the pail, putting two quarts of boiling water in its place. Put the carcass into this, and let it stay ten seconds, then take it out and put it in water nearly if not quite ice cold, letting it stay ten minutes. This, as has been explained, is "plumping," and gives the carcass a very plump and inviting appearance. Put a tablespoonful of salt into the cold water at the same time the fowl is put in. Hang up the fowl in a cool place until it is to be cooked or sold. Fowls treated in this way present an excellent appearance, and will keep several days without discoloration.

\section{PACKING AND SHIPPING.}

Carefully sew up all rents or torn places on the skin, wash clean in cool water, wipe dry and hang in a cool place until the animal heat is entirely out, before packing. Pack in clean barrels or boxes with clean straw, as follows: First a thin layer of straw and then a layer of poultry in the same posture in which they roost, then a layer of straw and another of poultry, and so on until the barrel or box is quite full, finishing with a layer of straw, which should be tucked firmly into any crevices in the sides. Nail the corners or head on securely, and mark carefully with the name and address of the dealer to whom you ship, not forgetting your name and address as shipper, and notify the dealer by postal or letter that 
you have shipped him one or more boxes or barrels of dressed poultry by freight or express, as the case may be. Always take a receipt from the freight or express agent, and ship so as to reach the market not later than Friday.

SHIPPING FOWLS ALIVE.

The great majority of fowls that are sent to market are shipped alive. Commission men prefer them in this way. They can kill them in lots as desired, and can dress them to suit the fancy or caprice of their customers. The Jews, who are now a large and important element in our cities, will not reat fowls, unless they are killed by a rabbi, and this makes a nonstant demand for live poultry. Fowls are generally shipped by express in old strawberry crates or small light 1)oxes of some sort. Before being sent off they should be given all the whole corn they will eat and be watered. Commission men are continually sending out circulars soliciting shipments. Some of these men are reliable and some are not. In general it may be said that it is safe to make consignments to firms that occupy stalls in public markets or who have been in business for a term of years. Men who have their offices or places of business in obscure quarters or who have lately started should be investigated. If they are all right the investigation will do them no harm, and if they are not all right it may save the shipper a loss he can ill afford. 


\section{CHAPTER XV.}

\section{Salad and Dressing.}

Never get too old to learn.

About as many failures in the poultry business come from keeping 100 fowls where there is room for only 25, as from any other source.

Sitting hens should not be allowed to dust in coal ashes, as the fine particles clog the pores in the egg shells. Dry earth is the best stuff for a sitting hen to dust in.

Kainit may be substituted for plaster to mix the manure in case a manure particularly rich in potash is wanted, and acid phosphate may be substituted for a rich phosphatic manure.

It is a good plan for a poultryman to keep a few standard remedies on hand all the time. Then if disease comes down upon him like the wolf on the fold he is in a measure prepared to meet it.

Lice multiply upon a sick fowl, because its vitality is so depleted that it cannot keep itself clean. Accordingly, when you remove a sick fowl to the hospital for treatment give it a good dusting with insect powder before you administer the medicine.

Introduce new blood from time to time, but do not introduce it indiscriminately. Find a man who is working along the same lines with yourself, and get your males from him. Breed in two years, and the third year send away to the same man for more males.

Green ground bone is a grand food for fowls, but it must be fresh and not fed in too great quantity. A correspondent writes that she lost 77 out of a flock of 94 beautiful chicks in three weeks by feeding ground bone that she bought of a local dealer. Probably the bone was tainted, or she fed too much.

Rats-Rats are naturally granivorous, and prefer corn to anything else. The poultryman should take advantage of this fact. Let him scatter a handful of whole corn about each rat hole, and the rat will not molest the chicks. It may seem rather expensive to feed rats corn, but it is not so expensive as it is to feed them on chicken meat. The poul- 
tryman should keep his eye peeled and his traps set for the rascals at the same time.

Eggs for hatching-How long may eggs for hatching safely be kept? To find out, go and ask the old hen that has stolen her nest. She will tell you that she has been hiding away eggs in the haymow or under the barn for at least three weeks, and that she expects every egg to hatch a chick. In a temperature of from 40 to 60 degrees, eggs may safely be kept at least three weeks before they are put in an incubator or under a hen. They should be turned every day.

Medium-Sized Fowl Called For-The market now calls for a medium-sized fowl. There was a time when the demand was for "old hoosiers," but that day has gone forever. I will tell you why. A bird dressing ten pounds has no more legs or wings than a bird dressing four or five. In the case of a large fowl part of the meat is left uneaten on the plate. In the case of a medium-sized fowl, a leg or wing is just right for an order. Shrewd buyers have learned that it is more profitable to buy two medium-sized fowls than one large one. There is still an occasional call for a large fowl, but the smaller ones are the better sellers.

Be Gentle-Be gentle with your birds. The hen is naturally timid and easily scared. When kindly treated, however: she becomes tame. Much of the pleasure in keeping fowls comes from having them so tame that they will let their owner work among them and even handle them at his will. One should never lose his temper, no matter how great the provocation. The hen is not a reasoning creature and often sorely tries her owner's patience. But if he never allows himself to get angry or treat her unkindly no matter what she may do. poultry keeping becomes not only a source of pleasure and profit, but a means of moral discipline not to be despised. "Blessed are the meek, for they shall inherit the earth," is a beatitude as true in the poultry business as it is elsewhere.

Precocious pullets seldom make phenomenal layers.

Dry planer shavings make the best material for nests.

Select a breed of fowl as you do a wife-to please yourself.

Don't go into the poultry business unless you have a "call" to it.

There is little danger of overfeeding hens after they begin to lay. 
Clear poultry manure, lightly sprinkled with coal ashes or land plaster to fix the ammonia is worth a dollar a barrel.

If your method of feeding gives good results don't change it because you happen to read of someone else. who feeds differently.

The fool knows it all to begin with. The wise man learns by his experience. The wisest man learns by his experience and the experience of others.

Read this book over time and again until you have thoroughly assimilated it. The closer you follow its teachings the more dollars you will make.

To get rid of the neighbor's cat, explode a torpedo under her tail whenever she comes around. This will scare the cat: but do her no permanent harm. The neighbor will appreciate the joke, and you will get rid of the cat and keep your neighbor's good will at the same time.

After a hen has laid an egg she cackles. Go and do thou likewise! If your birds have taken a prize at the county fair: cackle. If they have made a big egg record, cackle. If you have some fine stock to sell, cackle. In these days publicity and prosperity go together.

If you are in the business for eggs, and eggs alone, the sooner you get rid of your surplus "crowers" the better. I know a man who disposes of his cockerels, as soon as he can distinguish them from the pullets, for 10 cents each. He claims he is better off to sell them for this sum than to keep them.

Some think the shape of the egg determines the sex of the chick that is to be hatched. This is a mistake. The shape of the egg has no effect upon the sex of the germ is contains. A more plausible theory is that the shape of the egg will influence the shape of the chick that begins its life in it-a long egg giving a long, rangy chick, and a short, round egg a more blocky chick. This is worth investigating.

Don't be in too much of a hurry to have your chicks begin to roost. Put the roost in their house one foot from the floor and let them find out what it is there for themselves. Some adventurous chick will discover it after a while and get upon it; others will follow, and after a few weeks the whole flock will be roosting at night. Should there be any laggards drive them about with the soft end of the broom one or two nights until they are glad to get on the roost with the rest. 
The worst feature of the poultry business is its slavery. The poultryman must be on deck 365 days in the year, and in leap year 366. Sundays and holidays bring little relief, for the stock must be fed and watered, the eggs collected, and the chicks and sitting hens looked after as well as at other times. On small plants it is difficult to get a man to step in for a few days, who will not demoralize the whole thing. No man should go into the poultry business who does not have a real love for it; otherwise the monotony and slavery will become intolerable.

What rewards may a well-equipped poultryman expect? Not a fortune. You can count on your fingers, almost, the men who have made fortunes in the poultry business. And these men have made their money by selling birds and eggs to breeders rather than by catering to the regular trade. But a careful, industrious man, one who has a real liking for the work and has gone into it intelligently, may reasonably expect a good living, a pleasant home, health, and the independence that comes from being one's own master.

Novel Way to Break Up a Hen-After you have tried every other method you can think of to break up a hen, without avail, just tie a piece of red string or tape to her tail. Tie it so that there will be two loose ends, each about six inches long. to flutter behind. The hen will at once lose all interest in a sedentary life, and will start out of the house as if she was going to a fire. She will run until she is tired out, when she will stop; then she will start in and after a short rest run again: When night comes you will find her on the roost: cured. Take the ribbon off her tail, if she has not got it off herself. This may seem an heroic method, but as Shakespeare observes ;

\section{"Disease desperate grown \\ By desperate appliance are relieved, Or not at all."}

Economy, Practicability-In preparing this book I have been governed by two considerations: economy, practicability. By economy I mean not only frugality in the use of money. but also frugality in the use of time. I am aware that the great majority of those who keep fowls are not able to devote their whole time to the business, but must combine poultry keeping with other pursuits. I have had this class in mind in writing this book, and I have endeavored to show how the 
maximum of profit may be obtained with the minimum of effort. Every statement in the book has been tested by actual experience, and may be relied upon implicitly. I expect to learn as long as I live and to modify details from time to time; but never expect to depart radically from the principles laid down in these pages.

To Dust a Hen-With your left hand grasp the hen by the legs, and lay her' breast down upon a newspaper. The powder should be in a tin box with a handle and a perforated cover. Sprinkle the powder into the feathers around the vent, rubbing it in well. Work the powder into the feathers about the neck. Work the powder into the feathers on the sides and under the wings. Let the hen stand a moment, keeping your hands lightly around her so that she cannot get away. Return her to the roost and take another. After going through the pen shake the powder that has fallen on the newspaper into the can or package. One application kills the lice that are on the hen at the time, but in a week there will be another brood. The best poultrymen recommend dusting a hen at least three times, at intervals a week apart, and never admitting a strange hen into the pen without first dusting her thoroughly. One lousy hen will contaminate all the rest, and so it is necessary to be on one's guard all the time.

Causes of Disease-The more troublesome diseases of fowls, with their causes, may be summed up as follows: Roup -introduced by germs. Cholera-filth and overcrowding. Diarrhoea-damp houses, filthy houses and runs, overcrowding. Canker-dampness and filth. Diphtheria-roosting in draughts, also damp houses. Ulcerated throat-same. Consumption-neglected cold. Apoplexy, vertigo and epilepsyoverfeeding. Sore eyes-damp houses. Costiveness and constipation-improper food. Soft and swelled crop-overfeeding. Indigestion and dyspepsia-same. Pip-damp quarters. Bronchitis-same. Black rot-result of indigestion. Softshelled eggs-overfeeding.' Gout, rheumatism and crampdamp houses. Leg weakness-inbreeding and overfeeding. Bumble foot-high perches. Scaly legs-filth and damp quarters.

Whitewash-There is no better whitewash for outside work than that used by the United States government for public buildings, which is made as follows: Take half a bushel 
of unslacked lime and slack it with boiling water, covering during the process to keep in steam. Strain the liquid through a fine sieve or strainer, and add a peck of salt previously dissolved in warm water; three pints of ground rice boiled to a thin paste and stirred in while hot; half a pound of Spanish whiting, one pound of clean glue. Before the glue is added it should be dissolved in cold water and then brought to a state where it will flow freely by being placed over a slow fire in a small pot set in a larger one-the larger pot being filled with water. Add five gallons hot water to the mixture, stir well and let it stand a few days where no dirt can get into it. Apply hot. One pint of this whitewash will cover one square yard. Coloring matter may be added as desired. For cream color add yellow ochre; for pearl or lead color add lampblack or ivory black; for fawn color add proportionately four pounds of common lampblack; for common stone color add proportionately four pounds of raw umber to two pounds lampblack.

A Field Near Home-The man who does not have the capital to engage in the business on a large scale, or who does not feel competent to compete with breeders of established reputation, may largely increase his profits by imitating their methods within a limited area. Farmers are waking up to the importance of keeping thoroughbred stock. The average farmer does not feel that he can afford to pay $\$ 2$ or even $\$ 1$ for a sitting of eggs, but he will gladly pay 50 cents. The man who introduces a new and promising variety into his neighborhood, or who has a strain of any established breed noted for egg production, can count on a large sale of eggs for hatching around home. It is more profitable to sell eggs to the farmers for 50 cents' a sitting than to sell them for double that sum to customers out of town, for in the latter case there is the expense for advertising and baskets, the time consumed in packing the eggs and in correspondence.

How to Break Up a Sitting Hen-Don't be in a hurry to break up the sitting hen. She has laid long and well and needs a vacation before she starts in again. If it is summer put her out of the house and yard and let her forage for herself a few days. If it is winter or spring, put her in a pen built for broodies, give her a light feed of mash for breakfast, nothing for dinner, and the same for supper. Give her all the water 
she will drink. In a week she will be cured and come back to the flock with a good appetite, and in another week she will begin to lay. The philosophy of this method is that the scanty ration makes the hen uneasy and she forgets her desire for incubation. It won't hurt her to go a little hungry for a few days, for if she is in a condition to sit she has stored up plenty of fat and it will do her good to consume some of it. It is a fact not generally known that where no nest eggs are used and where the eggs laid are gathered two or three timès a day, hens are not nearly so likely to get broody as they are when they feel a clutch of eggs under them every time they go on the nest.

The two requisites of success in the poultry business are brains and pains.

The poultryman who expects winter eggs from immature or stunted pullets is going to be badly disappointed. It re'quires good food, good care and a good, steady growth from shell to maturity to develop winter layers.

\section{A SE'TTIN' HEN.}

When a hen is bound to set,

Seems as though 'tin't etiket

Dowsin' her in water till

She's connected with a chill.

Seems as though 'twas skursely right

Givin' her a dreadful fright,

Tyin' rags around her tail,

Poundin' on an old tin pail,

Chasin' her around the yard.

- Seems as though 'twas kinder hard

Bein' kicked and slammed and shooed

'Cause she wants to raise a brood.

'I sh'd say it's gettin' gay

Jest 'cause natur' wants its way.

-While ago my neighbor, Penn,

Started bustin' up a hen;

Went to yank her off the nest,

Hen, though, made a peck and jest

Grabbed his thumbnail good and stout,

-Liked to yanked the darn thing out.

Penn he twitched away and then

Tried again to grab the hen.

But, by ginger, she had spunk,

'Cause she took and nipped a chunk

Big's a bean right out his palm,

Swallowed it, and cool and calm

Histed up and yelled "Cah-dah!"

-Sounded like she said "Hoo-rah!"

Wal, sir, when that hen done that,

Penn, he bowed, took off his hat, -Spunk jest suits him, you can bet-

"Set," says he, "gol darn ye, SET."

- Holman F. Day in Lewiston Journal. 


\section{PAGE}

\section{A}

American Breeds Best.

\section{B}

Best Sexed Bircls..

Breeding for 200 Eggs............ 56-60

Breed from Best Birds........... 57

Brooder Care of ................6 68

Brooder, Install One.............66 66

Brooder. Removing Chicks to..... 67

Brooder, Secrets of Success With.. 67 Brooder Chicks, How Author Feeds. 68 Brooder Chicks, Another Man's Way 69

\section{C}

Carbohydrates . 35

Chicks and Their Care.........66-71

Chicks, with Hens................ 70

Chicks, Diseases of ............. 73

Chicks, When to Hatch............ 71

Cholera ........................ 77

Colds and Bronchitis............... 74

Colony - Plan................. 8

Community Plan.............. 9

Colony-Community Plan........... 12

Crop Bound................... 78

Crosses

D

Diarrhœa

Diseases, Causes of .............. 93

Diseases, the More Common...... 72-80

Drinking Water................... 24

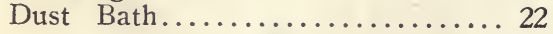

\section{$\mathrm{E}$}

Egg Eating.

Egg Foods and Tonic.

Eggs, Feeding for..

Eggs in Fall and Winter........41-45

Egg Production, Conditions of..... 7

Egg Records, How Wrecked...... 5

Egg Type................... 7

End of 200-Egg Hen......... 85-88

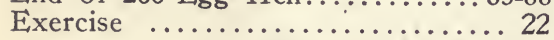

\section{F}

Fats

Feeding, a Woman's Way........... 32

Feeding, Caution............... 29

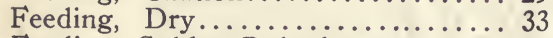

Feeding, Golden Rule for.......... 30

Feeding How Much............... 26

Feeding, Summer Method......... 29

Feeding, Variety Necessary........ 28

Feeding, Winter Method.......... 27

Foods and Food Values........34-40

$$
\text { G }
$$

Grit, Charcoal and Oyster Shells.... 23

Green Food.................. 37

\section{$\mathrm{H}$}

Hen Persuader, Mr. Fox's......... 45

Heredity $\ldots \ldots \ldots \ldots \ldots \ldots \ldots \ldots . \ldots 4$

Home of 200 -Egg Hen........... $8-17$

Incubatiọn, Artificial and Natural. . 61-65

Incubator or Hen..............6. 61

Incubator, Get a Good One.

\section{$\mathrm{K}$}

PAGE

Killing and Dressing

L

Leg Bands.................66 61

Lice and Red Mites................. 20

Liver, Diseases of................. 77

\section{M}

Male, Importance of........... 58

Manure, Poultry................... 84

Mature Birds, Breed from.......... 85

Moulting .................. 79

Montana Experiment Station House. 12

$\mathrm{N}$

Natural Hen Incubator.

Non-Layers

\section{$P$}

Packing and Shipping

Piano Box Houses................ 16

Prize Method of Feeding......... 45

Products and By-Products....... 81-84

Preserving Eggs, Methods of.... 82-84

Pullets, to Start Laying.......... 45

\section{$\mathrm{R}$}

Rats ................... 36

Rations, Balanced, etc.............. 36

Reproduction, Conditions of.......4 47

Reproduction, Sex Element in...... 48

Roup

S

Salad and Dressing

Sanitation in Egg Production.......18-24

Scalding Fowls................ 87

Sex Element in Eigg Production....46-51

Scaly Legs................... 78

Shipping Live Stock........... 88

Sitting Hen. Care of............. 64

Sitting Hen, to Break Up......... 95

Successful Men, How Some Feed... 30

Summer, Sanitation in........... 24

Sex, Law of ............... 49

Sex, Selection by............ 49

Sick Birds, Segregate........... 72

Sickness, Beginning of......... 72 $\mathrm{T}$

Tables ......................39-40

Testing Eggs....................... 64

Tonic, A Good................ 78

Things to Bear in Mind........... 38

Trap Nest and Its Uses......... 5255

Two Hundred Egg Hen........... 3-7

\section{V}

Varieties, How Many............ 5

Vermin, To Rid House of........ 21

W

Water Test................65

Winter Eggs from Pullets........ 41

Winter Eggs, Feeding for......... 43

Winter Eggs, Why Not Fertile..... 60

Whitewash, Government......... 93 $\mathbf{Y}$

Yard, Poultry. 


$5 F 487$
$w 3$
$9+2$

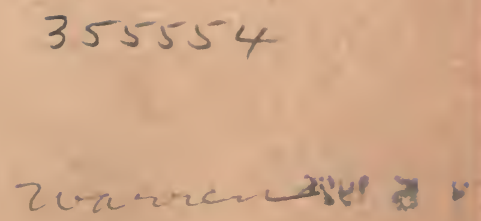

UNIVERSITY OF CALIFORNIA LIBRARY 
